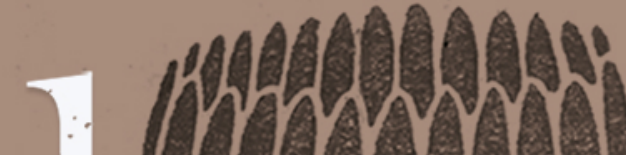

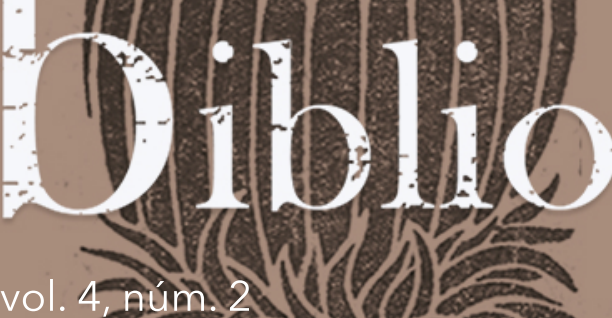

vol. 4, Aum?2

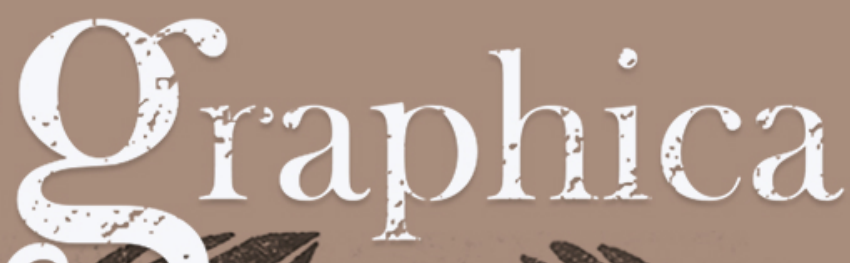

segubdo-semestre 2021 s.

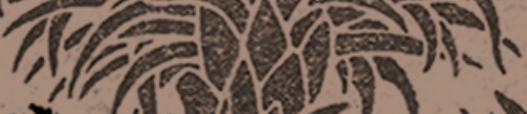
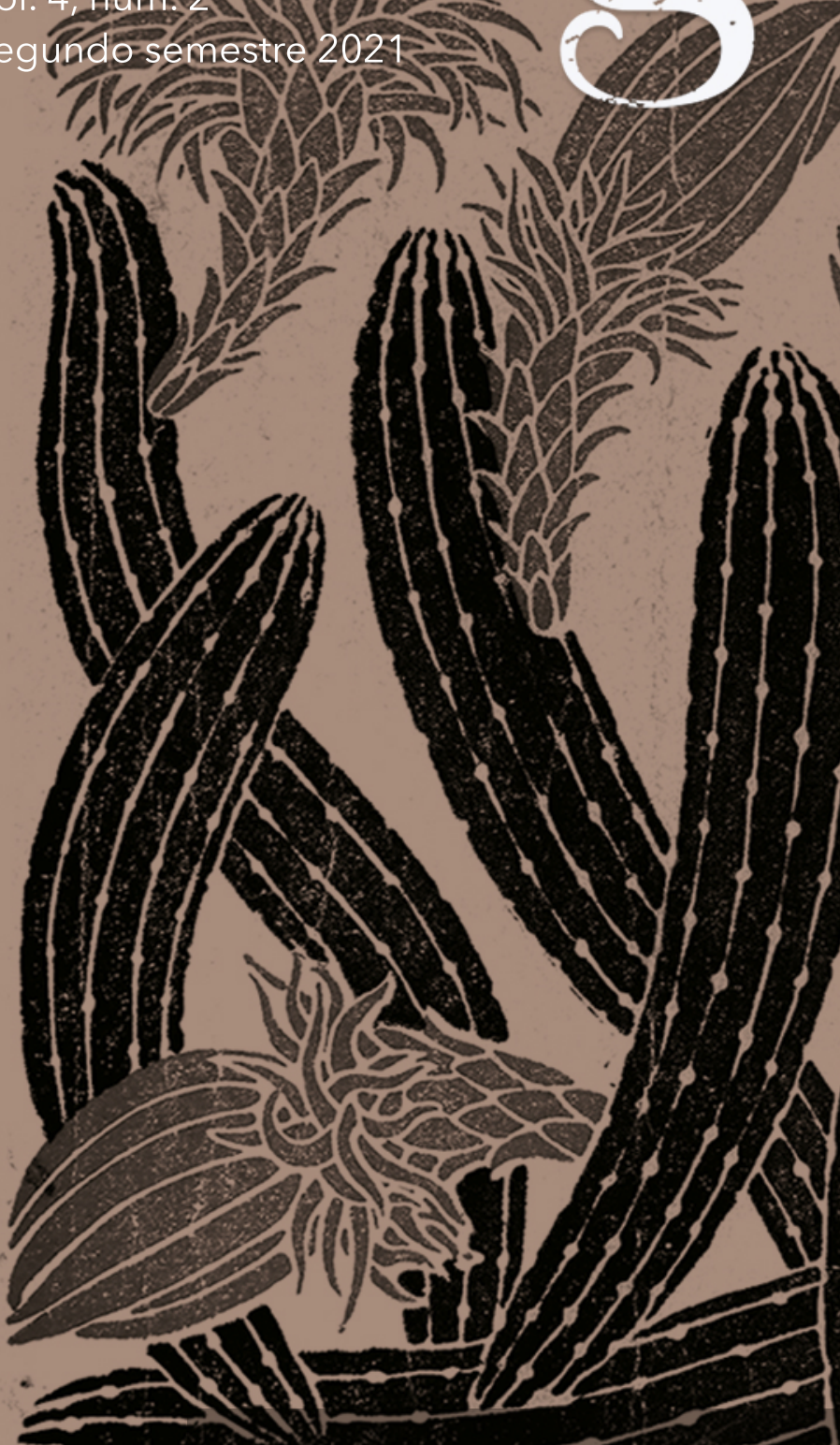

ISSN $2594-178 X$
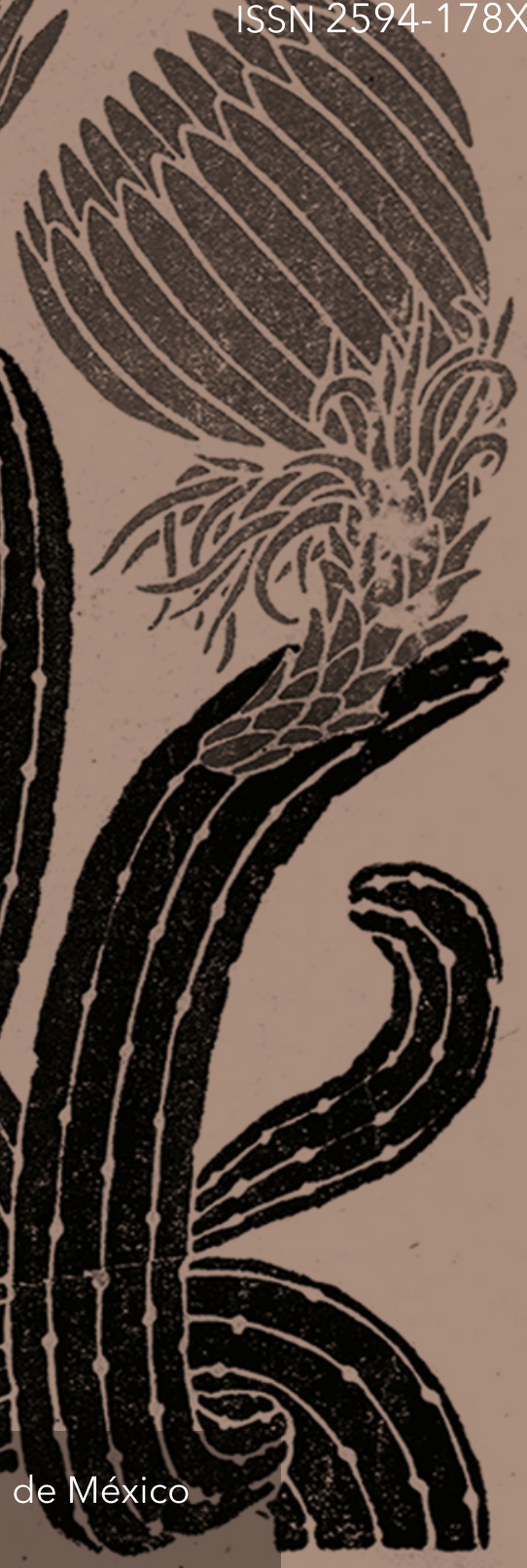


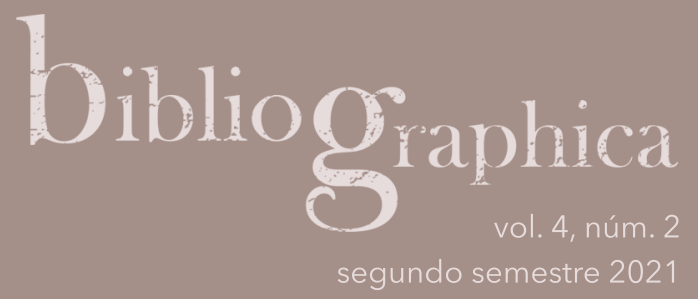

\section{El Dr. Atl y la revista América: un programa estético y editorial antiimperialista}

Dr. Atl and América Magazine:

An Anti-Imperialist Aesthetic and Editorial Program

\section{Natalia de la Rosa}

Universidad Nacional Autónoma de México, Instituto de Investigaciones Filológicas,

Ciudad de México. México

nataliadelarosa83@gmail.com

ORCID: https://orcid.org/0000-0003-3367-0345

Recepción: 09.03.2021 / Aceptación: 14.07.2021

DOI: https://doi.org/10.22201/iib.2594178xe.2021.2.104 
Resumen

Palabras clave

Abstract

Keywords
Éste es un acercamiento a la revista América (1926) que revisa la organización de los cinco números publicados para exponer el programa económico-estético orquestado por su director, Gerardo Murillo, Dr. Atl. Destaca la labor editorial, de diseño y escritura de Atl, así como su desarrollo. Entre los temas de la revista sobresalen el arte popular, el urbanismo, la raza, la producción artística y la política continental. El texto señala las conexiones nacionales y redes intelectuales diseñadas por Atl para revivir la Liga Internacional de Escritores y Artistas, activa en París entre 1912-1913 y vinculada a la agrupación y publicación anarquista de L'Action d'Art, coordinada por Gérard de Lacaze-Duthiers y el poeta André Colomer. Asimismo, subraya la importancia de la propuesta de producción de nuevos repertorios y diccionarios locales y regionales, a partir de la colaboración de autores como el poeta Horacio Zúñiga y el pedagogo y lingüista Delfino Torijano.

Gerardo Murillo; revistas culturales; literatura mexicana; arte mexicano; antiimperialismo.

This paper analyzes the Mexican magazine América (1926) and reviews the organization of its five numbers published in order to expose the political-aesthetic program defined by its director, artist Gerardo Murillo, known as Dr. Atl. The text underscores Atl's editorial, designing and writing work, as well as his development. The magazine's subjects are popular art, urbanism, race, artistic production and continental politics, among others. This article points out the national connections and intellectual networks designed by Atl as an intent for reviving the International League of Writers and Artists, which was active in Paris during 1912-1913 and linked to the anarchist group and the publication L'Action d'Art, coordinated by Gérard de Lacaze-Duthiers and André Colomer. Likewise, here the importance of the proposal for the production of new local and regional repertoires and dictionaries is underlined, based on the collaboration of authors such as poet Horacio Zúñiga and pedagogue and linguist Delfino Torijano.

Gerardo Murillo; cultural magazines; Mexican literature; Mexican art; anti-imperialism. 


\section{Introducción ${ }^{1}$}

América. Una estrategia editorial continental

En 1926 el pintor, geólogo, vulcanólogo y etnógrafo jalisciense Gerardo Murillo (1875-1964), Dr. Atl, fundó la revista América. Órgano de la Liga de Escritores de América. Su título reveló desde un inicio la ambivalencia y variaciones estratégicas que constituyeron la idea y funcionamiento general de la publicación. La elección del nombre puntualiza un espacio de incidencia y una táctica de regionalización. La adscripción reitera un condicionamiento geográfico y, al mismo tiempo, señala un intento de acción colectiva y gremial, al remitir a un grupo específico como orquestador del proyecto.

Cuando el Dr. Atl presentó América, el paisajista contaba con una amplia experiencia en la organización de publicaciones de diversa índole, ya fueran periódicas, hojas volantes, poemarios y repertorios artísticos variados. Desde París, entre 1912 y 1913, Murillo organizó el periódico L'Action d'Art con un grupo de intelectuales anarquistas. ${ }^{2} \mathrm{Al}$ regresar a México, en 1915, en papel de estratega y dirigente de la causa carrancista, el artista y revolucionario coordinó dos publicaciones periódicas, La Vanguardia. El Diario de la Revolución, fundada en Orizaba, y Acción, publicada en Guadalajara, seguidas por Acción Mundial, en 1916 y 1917, periódico activo desde la Ciudad de México. En este mismo periodo comenzó la redacción de manifiestos y panfletos diversos. De los folletos de corte propagandístico apenas hay noticias.

El biógrafo del autor, Antonio Luna Arroyo, recogió algunos títulos y lamentó la pérdida de mucha de esta información. Entre ellos destacan: Álvaro Obregón: Sonora y la Revolución, Atl: Palabras de un hombre al pueblo de América y Alberto J. Pani: La higiene en México. ${ }^{3}$ En 1921, al regreso de un exilio de dos años en Estados Unidos, el Dr. Atl dio comienzo a la redacción de libros y monografías, al distanciarse de la gesta revolucionaria tras el rompimiento

\footnotetext{
${ }^{1}$ Becaria posdoctoral por la Coordinación de Humanidades en el Instituto de Investigaciones Filológicas, UNAM, con asesoría de la doctora Yanna Hadatty Mora.

${ }^{2}$ Años atrás, en un primer viaje a Italia, Gerardo Murillo tuvo un acercamiento al Órgano del Partido Comunista, el periódico Avanti y, según expresó, a las enseñanzas del pintor Enrico Ferri. Sin embargo, no fue sino hasta la siguiente década cuando organizó directamente publicaciones impresas, tanto en París como en México. Cfr. Olga Sáenz, El símbolo y la acción. Vida y obra de Gerardo Murillo, el Dr. Atl (México: El Colegio Nacional, 2017), 47.

${ }^{3}$ Antonio Luna Arroyo, El Dr. Atl: paisajista puro. Sinopsis de su vida y su pintura (México: Cvltvra, 1952).
} 
y caída del carrancismo. Este momento significó el ascenso del grupo sonorense al poder, el cual tenía una imagen desacreditada del pintor, a quien el presidente Álvaro Obregón (1880-1928) veía como un actor "inofensivo".4

Las obras escritas en esta etapa son: el poemario Sinfonías del Popocatépetl, el Catálogo de la colección Alberto J. Pani, los dos tomos de las Artes populares en México y el libro Iglesias de México, publicadas entre 1920 y 1922. El conjunto fue complementado con ¡Arriba!, iArriba!, descrito por Antonio Luna Arroyo como una suerte de autobiografía, "un canto a la vida, a la energía y a la dicha de vivir (1922)". ${ }^{5}$ Destaca en esta lista la presencia de Alberto J. Pani (1878-1955), figura fundamental en el regreso de Atl a México, ya que fungió como enlace e intermediario entre el pintor y el gobierno, al ser un excarrancista partícipe relevante del gobierno y quien convenció a Álvaro Obregón de tomar en cuenta al artista en el proyecto cultural nacional, alejado ya de cualquier decisión política directa. ${ }^{6}$

Después de la década de 1920, Atl intercala sus actividades entre la escritura y la pintura, aunque modifica los modos de acercamiento y expectativas, vuelco que tomará forma y llegará a consolidarse en una inclinación abiertamente fascista y antisemita, tendencia que el pintor también difundirá por medio del libro y múltiples folletos, en el contexto de la Segunda Guerra Mundial. Ese momento, al igual que la organización del magazine, respondió a la defensa del territorio nacional y continental, ' donde la relectura de ciertos autores, específicamente Gabriele D'Annunzio, sustentó un nihilismo dinámico con "motivaciones fundamentalmente ideológicas". ${ }^{8}$

Analizar la breve historia de América resulta determinante para comprender un proceso previo a la apología fascista. Durante los gobiernos de Álvaro Obregón (1920-1924), Plutarco Elías Calles (1926-1928) y Emilio Portes Gil

\footnotetext{
${ }^{4}$ Sáenz, El símbolo y la acción, 307.

${ }^{5}$ Luna Arroyo, El Dr. Atl.

' Sáenz, El símbolo y la acción, 307.

${ }^{7}$ Esos textos son: Dr. Atl, A los pueblos de América. Se impone la defensa del continente contra la política de Roosevelt (México: s. e., 1941); Dr. Atl, Ante la carroña de Ginebra (México: Polis, 1938); Dr. Atl, Paz, neutralidad, guerra (México: s. e., 1939); Dr. Atl, Quiénes ganarán la guerra (México: s. e., 1940).

${ }^{8}$ Ángel Sánchez Rodríguez, "Il Superuomo ed Energeia, la decima musa. La influencia de D’Annunzio en la aproximación ideológica del Dr. Atl al fascismo", en De Dante a Camilleri: Estudios sobre literatura y cultura italiana, Cátedra Extraordinaria Italo Calvino, XIII Jornadas Internacionales de Estudios Italianos, 6-10 de noviembre de 2017 (México: UNAM, FFyL, 2020), 215-217.
} 
(1928-1930), el Dr. Atl encabezó distintos planes económicos, políticos, científicos y estéticos para poner en marcha una propuesta alternativa a las reformas oficiales, que actualizó las demandas alcanzadas por el movimiento constitucionalista. ${ }^{9}$ Las tentativas reformistas de Atl, centradas en la legislación agraria, ${ }^{10}$ fortalecieron -a medida que avanzó la década- un modelo palingenésico, ${ }^{11}$ visible en sus acercamientos paisajísticos, de planificación urbana y escritura de ciencia ficción.

En estas primeras décadas del siglo XX observamos a un Dr. Atl que navega por múltiples espacios en intervalos muy cortos, unas veces coherentes y muchas otras contradictorias entre sí: durante los años 10, da un salto natural del anarquismo y del sindicalismo al movimiento revolucionario; en la década de los 20, después de formar parte de la resistencia antiimperialista, incursiona rápidamente en la promoción de la inversión norteamericana en tierras mexicanas; ya entrados los años 30, pasa de una discreta cercanía con el régimen al momento de la fundación del Partido Nacional Revolucionario (PNR), ${ }^{12}$ a la defensa de los regímenes fascistas en medios como La Reacción. ${ }^{13}$

Entre 1930 y 1950 el paisajista abocará la escritura a las novelas de ciencia ficción, a los cuentos, a la exploración del formato autobiográfico y al estudio geológico en forma de registro de campo, o como estudios económicos de los recursos del suelo nacional. ${ }^{14}$ Muchos de estos títulos tuvieron poca repercusión real -intervención que fue más bien indirecta-, aunque varios tengan una pre-

\footnotetext{
${ }^{9}$ Rosalía Romero, "Anarchism and Visual Culture in Mexico, 1910-1950" (tesis de doctorado, Durnham, Duke University, 2019), 100.

10 lbid., 9-10.

${ }^{11}$ Sánchez Rodríguez, "Il Superuomo ed Energeia...".

12 Renato González Mello, "Diego Rivera, José Vasconcelos y los murales de la SEP", Colegio Nacional, marzo de 2021, Fototeca Nacional. González Mello presenta en un amplio estudio dedicado a la historia del Palacio Nacional y la construcción del canon estético oficial, una fotografía que evidencia las alianzas entre los artistas Diego Rivera y el Dr. Atl con Emilio Portes Gil y otros políticos que darán forma a la revolución institucional a través de la fundación del PNR, en 1929. Esta imagen forma parte del acervo de la Fototeca Nacional, acceso el 20 de julio de 2021, https://www.youtube.com/watch?v=bB8SGYN1y-c

${ }^{13}$ Sánchez Rodríguez, "Il Superuomo ed Energeia...", 215.

${ }^{14}$ Entre los estudios destacan: Dr. Atl, Petróleo en el Valle de Méjico: Una golden line en la altiplanicie de Anáhuac (México: Polis, 1938); Dr. Atl, ;Oro! Más oro: El mundo lo necesita: México puede dárselo (México: Edición Botas, 1936); Dr. Atl, Cómo nace y crece un volcán (México: Ed. Stylo, 1950).
} 
tensión de reinserción eficaz. ${ }^{15}$ Dichas expectativas quedaron plasmadas sólo como una proyección ideal. ${ }^{16}$

Este periodo intermedio hacia los guiños autoritarios estuvo inmerso en una reflexión y adaptación respecto al significado mismo de la "Revolución". A mediados de 1920 el artista mexicano realizó un viraje táctico hacia una tendencia generalizada en el continente, dedicada a organizar acciones en contra de la "maquinaria imperial". ${ }^{17}$ Como el propio pintor señaló, América significó una desordenada aventura editorial que buscó ofrecer una posibilidad alterna al proyecto revolucionario: "fuera de estas colaboraciones y de algunas iniciativas revolucionarias, como la forma de un diccionario americano, la revista tenía poco interés y estaba muy mal organizada tipográficamente, a pesar de lo cual tuvo una gran circulación". ${ }^{18}$

Las líneas de análisis que proponemos para estudiar la revista América como proyecto de publicación se centran en dos ejes: uno que busca explicar la variación del formato, que pasó de la producción de publicaciones periódicas y folletos propagandísticos al modelo del magazine, y el énfasis geopolítico y económico de la revista, que anuncia y presume un alcance hemisférico basado en las redes políticas, estéticas y en el apoyo intercontinental. Así, damos continuidad a un enfoque centrado en las redes intelectuales, como posibilidad de apertura al entendimiento de los movimientos literarios y artísticos de la vanguardia local. ${ }^{19}$

${ }^{15}$ De cierta forma, las ideas urbanas y utópicas del Dr. Atl alcanzaron el plano material y práctico a través de los proyectos constructivos y las investigaciones técnicas del empresario español Manuel Suárez y Suárez, dueño del Hotel Casino de la Selva. Daniel Vargas Parra ha rastreado los vínculos de colaboración y mecenazgo entre ambas figuras y ciertos remanentes de la propuesta de la Ciudad de Cultura del pintor en el proyecto inconcluso del Hotel México 2000. De la ambiciosa propuesta de urbe moderna solamente quedó construido y activo el Polyforum Cultural Siqueiros (1970), en el Parque de la Lama. Daniel Vargas Parra, "Ecuación Eureka. Del expediente Suárez y la transformación de la materia" (texto inédito). Agradezco al autor la oportunidad de revisar esta investigación.

${ }^{16}$ Cuauhtémoc Medina, Olinka: la ciudad ideal de Atl (México: El Colegio Nacional, 2018).

${ }^{17}$ Alan Knight, "Empire in the Americas. Historical Reflections", en Empire and Dissent. The United States and Latin America, ed. de Fred Rosen (Durham, NC: Duke University Press, 2008), 24.

${ }^{18}$ Dr. Atl, Gentes profanas del convento (México: Senado de la República, 2003), 215. No ha sido posible comprobar si esta presunción de circulación es certera o una de las tantas exageraciones del autor.

19 Natalia Majluf y Beverly Adams, eds., Redes de vanguardia. Amauta y América Latina, 1926-1930 (Lima; Madrid: Asociación Museo de Arte de Lima - MALI / Museo Nacional Centro de Arte Reina Sofía, 2019). 
La revisión del ideario y formación de la revista permite señalar una tensión entre cosmopolitismo y regionalismo, a partir de una propuesta estética y discursiva. ${ }^{20}$ Esta dicotomía resulta evidente en el interés por crear un mercado americano de forma paralela a un diccionario local; o en los diálogos propuestos entre arte y artesanía, o entre literatura e impresos populares. ${ }^{21}$

Durante la experiencia de exilio entre Los Ángeles y Baja California en 1916, Atl reafirmó una labor transfronteriza y de formación de lazos de solidaridad. ${ }^{22}$ De esta forma, dio paso a un discurso antiimperialista, basado en un imaginario transnacional y en la producción colectiva como resistencias frente a la ingeniería imperial. ${ }^{23} \mathrm{Al}$ reclamar una acción sobre el territorio hemisférico, como denota el nombre mismo de la publicación, el Dr. Atl puso en marcha un modelo de organización continental en aras de una restitución económica y cultural, bajo los lemas "Defensa y expansión de la cultura del continente" y "Unificación del pensamiento continental". Insistió en que este proyecto editorial surgió con el fin primordial de llevar a cabo una defensa de la lengua y confirmar la relevancia de la labor editorial, esta vez enfocada en consolidar un mercado continental.

América tuvo una expectativa tanto comercial como educativa, por ello intentó dar cierto protagonismo a los anuncios publicitarios y secciones recreativas. No obstante, el peso retórico de Atl y la exhibición constante de un programa ideológico, harán de la revista un espacio complejo y un tanto confuso respecto a su público lector ideal. Es decir, intentó tener el nivel de difusión de las publicaciones comerciales como Azulejos, Revistas de Revistas o el Universal Ilustrado, a la vez que un contenido especializado en temas artísticos, literarios y antropológicos como el que presentaban Forma, Mexican Folkways u Horizonte. ${ }^{24}$ Esta ambivalencia dio como resultado un episodio corto y olvidado en

\footnotetext{
20 Jorge Schwartz, Las vanguardias latinoamericanas. Textos programáticos y críticos, 1 a. reimpr., trad. Estela Dos Santos (México: FCE, 2002), 62.

${ }^{21}$ Viviana Gelado, Poéticas de la transgresión: vanguardia y cultura popular en los años veinte en América Latina (Buenos Aires: Corregidor, 2007), 80.

22 Romero, "Anarchism and Visual Culture in Mexico...", 19-22.

${ }^{23}$ Fred Rosen, "Introduction" a Empire and Dissent. The United States and Latin America, American Encounters/Global Interactions (Durnham, NC: Duke University Press, 2008), 6. https://doi.org/10.2307/j.ctv120qs80.

${ }^{24}$ Fernando Ibarra Chávez, Escritores de imágenes y pintores de discursos. Literatura y crítica de arte en la prensa cultural de México (1900-1930), Heúresis (México: UNAM, FFyL, DGAPA, 2020), 51, PDF, acceso el 5 de agosto de 2021, http://ru.atheneadigital.filos.unam. $\mathrm{mx} / \mathrm{jspui} /$ handle/FFYL_UNAM/2502.
} 
la trayectoria del pintor. No obstante, la complejidad y cantidad de capas que permean la edición, la determina como un caso de estudio relevante. Así, el presente trabajo completa un vacío en el repertorio intelectual y político del artista, ${ }^{25}$ al tiempo que suma a la investigación sobre la cultura impresa, las revistas culturales y los lenguajes utópicos en México y América Latina.

\section{La Liga de Escritores y Artistas de América}

En 1926 el gobierno de Plutarco Elías Calles entró en un momento de consolidación y separación del modelo instaurado por el régimen de Álvaro Obregón. Desde que Calles asumió la presidencia, el régimen creó una imagen de socialista radical, por la cual obtuvo simpatía de las organizaciones obreras institucionalizadas, como la Confederación Regional Obrera de México (CROM). Sin embargo esta radicalidad, evidente en el estallido de la Guerra Cristera, también detonó desestabilidad respecto a los Tratados de Bucareli, dedicados a restaurar la relación mexicano-estadounidense. ${ }^{26}$

Pablo Yankelevich explica la atención que México tuvo en esos momentos a nivel mundial, tanto por las expectativas generadas respecto a los efectos de la Revolución como por las tensiones al interior y exterior que el país enfrentaba. Para el historiador, la forma en que el callismo encaró la política exterior dio la pauta para que México fuera, ante la mirada internacional, el difusor por excelencia del ideario comunista en América Latina. ${ }^{27}$

${ }^{25}$ Entre los estudios generales y monografías dedicadas al artista destacan: Luna Arroyo, El Dr. Atl, paisajista puro; Dr. Atl, pinturas y dibujos, pról. de Carlos Pellicer (México: Fondo Editorial de la Plástica Mexicana, 1974); Dr. Atl, inventor del paisaje (México: Fomento Cultural Banamex, 1978); Jorge Hernández Campos et al., Dr. Atl: Conciencia y paisaje (México: UNAM, Dirección General de Difusión Cultural / INBA, Museo Nacional de Arte, 1985); Beatriz Espejo, Dr. Atl: El paisaje como pasión (México: Fondo Editorial de la Plástica Mexicana, 1994); Sáenz, El símbolo y la acción.

26 Pablo Yankelevich, Miradas australes. Propaganda, cabildeo y proyección de la Revolución mexicana en el Río de la Plata (México: INEHRM / SRE, 1997).

${ }^{27}$ Yankelevich explica cómo la actitud desafiante del callismo en contra de Estados Unidos contrastó con la apertura directa y reconocimiento que el régimen revolucionario ofreció al gobierno soviético, como pudo observarse en el generoso recibimiento de Alejandra Kollontai en México, en 1924. Por otro lado, es importante señalar el peso que la presencia mexicana tuvo a través de las giras de José Vasconcelos (1882-1959) por Latinoamérica. Su labor desde la Secretaría de Educación Pública -explica Pablo Yankelevich- implicó un "pacto de los intelectuales con la Revolución al servicio de una reforma cultural que no reconoce antecedentes en América Latina". El interés por la Revolución mexicana y el espiritualismo vasconceliano adquirieron un papel protagonista en el ámbito internacio- 
En el caso del Dr. Atl, la década de 1920 representó un repliegue en su radicalismo, como respuesta al triunfo de la revolución bolchevique. ${ }^{28}$ Más que olvidados, como señala Olga Sáenz, los ideales del socialismo italiano y el anarquismo individualista tendrán variaciones sustanciales y reformulaciones ante las condiciones del contexto nacional e internacional que enfrentó el pintor. En las siguientes décadas tomará una postura claramente conservadora y de retaguardia. Las tendencias callistas a favor del modelo soviético y la desconfianza que Atl expresó ante la institucionalización de la Revolución generaron una clara tensión entre el régimen revolucionario y el artista. Es en este contexto cuando nace la edición de la revista América.

La Liga de Escritores de América fue creada por el Dr. Atl en 1926. Según relató en sus memorias, la iniciativa coincidió con una salida momentánea del Convento de la Merced, donde residía desde años atrás. El traslado a unas caIles contiguas del centro fue el pretexto perfecto para organizar, con un grupo de amigos e intelectuales cercanos, la Liga de Escritores, una suerte de centro de operaciones y paso obligado para cualquier intelectual que visitara la capital mexicana: "abrimos nuestros salones para recibir a los intelectuales extranjeros que llegaban a México, cualquiera que fuese su tendencia: grupos de periodistas cubanos, novelistas franceses e italianos, escritores neoyorquinos, celebridades de la comedia francesa, etcétera". ${ }^{29}$ El propósito del espacio fue generar distintas redes y funcionar como un propagador de ideas a través de conferencias, debates y estudios diversos, donde el órgano oficial, una revista, resultó el complemento y cohesionador del proyecto.

Gerardo Murillo hizo en su juventud dos viajes por Europa. Entre 1899 y 1903, por medio de una beca oficial, pudo organizar un primer viaje de estudios a Italia. A su regreso, ya con fama de participar en movimientos políticos, mostró un ataque directo a través de la crítica de arte con el seudónimo de Dr. Orange. Como parte de este proceso es recordada su participación en Savia Moderna (1906), revista donde conoció a Alfonso Cravioto y Luis Castillo Ledón -colaboradores en América-, y en la muestra de arte mexicano, bajo el marco

\footnotetext{
nal y generaron un espejeo constante frente a la Revolución rusa. Además, el proyecto de mestizaje expuesto en La raza cósmica generó impacto en la posibilidad de una "síntesis de todas las razas, cuya cuna hispanoamericana ponía al continente a la vanguardia de una nueva civilización de concordia, prosperidad y renovada espiritualidad". Yankelevich, Miradas australes, 312 .

${ }^{28}$ Sáenz, El símbolo y la acción.

29 Dr. Atl, Gentes profanas del convento, 214.
} 
del Centenario de la Independencia 1910. Al mismo tiempo, desde la Academia de San Carlos comenzó un movimiento contrapuesto a las políticas oficiales de la enseñanza y exhibición. Pocos años después hizo un segundo viaje a Europa y participó activamente en la fundación de la publicación y movimiento de "los camaradas" de L'Action d'Art (1906-1920), encabezados por el teórico anarquista-individualista Gérard de Lacaze-Duthiers y el poeta André Colomer. ${ }^{30}$

El rescate que Cuauhtémoc Medina ha hecho de la planeación de una ciudad ideal que el pintor mexicano buscó organizar en esos años desde París, y que continuó durante décadas, arroja algunos datos importantes respecto a la historia de la Liga de Escritores en su vínculo con L'Action d'Art. ${ }^{31}$ Para Medina, la obsesiva inclinación de Atl por agrupar a jóvenes intelectuales -a partir del concepto de "Aristocracia" - estuvo siempre relacionada con el proyecto de fundación de una Ciudad de Cultura. ${ }^{32}$ Los puntos a destacar de este momento corresponden a la relevancia y usos de la publicación periódica como mecanismo de propaganda y acción, al igual que a la estructura de la actividad grupal, ambas justificadas bajo las condiciones que el anarquismo de Colomer y Lacaze-Duthiers representan, aspectos que repercutieron -como señaló Atl explícitamente- en el programa y concepción de la revista América. ${ }^{33}$

Para Olga Sáenz, la Liga de Escritores tuvo como antecedente más directo la Confederación Revolucionaria que Atl buscó organizar en Veracruz en 1915 para unir a obreros, militares e intelectuales en un mismo organismo. ${ }^{34}$ La fundación de la Confederación, a decir de Sáenz, convocó a un grupo de artistas e intelectuales en el órgano periódico titulado Acción Mundial. La autora reitera

${ }^{30}$ Mark Antliff, "Cubism, Futurism, Anarchism. The 'Aestheticism' of the L'Action d'Art Group", Oxford Art Journal 21, núm. 2 (1998): 101-120.

${ }^{31}$ Mark Antliff rastreó por primera vez el programa teórico-político de L'Action d'Art y delineó los enlaces del grupo con escritores y artistas vinculados al simbolismo, cubismo y futurismo, figuras como Guillaume Apollinaire, Gino Severini y Albert Gleizes. Esa postura, a decir del autor, tomó una de sus dos formas posibles: "la violencia armada de la reprise individuelle o una revuelta metafórica contra las convenciones sociales en favor de la autoexpresión". En el original: "The armed violence of reprise individuelle or a metaphorical revolt against social conventions in favor of self-expression".

${ }^{32}$ Cuauhtémoc Medina, Olinka: la ciudad ideal de Atl 19.

${ }^{33}$ Antliff, "Cubism, Futurism, Anarchism...". En su momento, los impresos de L'Action d'Art y su suplemento/brochure L'Action d'Art Revue tuvieron la función de exhibir un programa político, al tiempo que alzaron tanto polémicas como defensas colectivas, durante una actividad intermitente entre 1913 y 1919.

${ }^{34}$ Sáenz, El símbolo y la acción. 
que la propuesta de reunión de escritores continuó en 1921, con la tentativa fallida de un Congreso Nacional de Escritores.

Sin embargo, no sería sino hasta 1925 -con apoyo de Luis Castillo Ledón, Rubén M. Campos y Luis Rosado Vega-cuando aseguró la reunión de un grupo al interior de una versión renovada de la primera liga europea, a través de un "Ilamamiento a los escritores mexicanos".

Durante su paso por México, Alejo Carpentier confirmó el papel de la liga como un espacio modesto, pero relevante para el encuentro de artistas, escritores e intelectuales. Al escribir sobre el muralista José Clemente Orozco, expresó: "Conocí por primera vez a José Clemente Orozco en el austero salón de la Liga de Escritores de América -ese rincón tan cordial que se cobija en una ruinosa casona cuya mera sombra es ya reconfortante para los que piensan- ${ }^{\text {". }}{ }^{35}$ En este mismo cuerpo de notas, ${ }^{36}$ el escritor cubano confirmó que Atl era distinguido como el presidente de la Liga y que usó este medio para la planeación de un ambicioso y misterioso proyecto: "Mientras los ojos secos y nerviosos del Dr. Atl poblaban el ambiente de una teoría de ángulos, y su verbo cáustico y certero pirueteaba en defensa de no sé qué idea audaz - nuevas y audaces son siempre las ideas defendidas por ese viejo, joven entre los jóvenes- el pintor sonreía distraídamente".37

El formato de publicación periódica de L'Action d'Art (París, 1913) y La Vanguardia (Veracruz, 1915) dio la pauta para diseñar un nuevo modelo de provocación y expresión directa. La variación al magazine a través de América (Ciudad de México, 1926) evidencia un cambio de estrategia y expectativas. Al finalizar el movimiento armado y en un contexto de formación de instituciones y difusión de la Revolución hacia el exterior, la revista América tuvo como principal expectativa evidenciar lo que denominó una "coalición de acción", dedicada a dar salida a proyectos diversos que serían apoyados por todo un bloque internacional.

Desde un inicio el magazine expresó un objetivo fundamental, al ser su propósito albergar y difundir productos de un mismo sello editorial y de un solo grupo, el cual pretendía extender como red a otros proyectos y espacios. La Liga osciló, entonces, entre un seleccionador de temas y autores, y una oficina o institución de propaganda "intercontinental". ${ }^{38}$

\footnotetext{
${ }^{35}$ Alejo Carpentier, "Creadores de hoy. El arte de José Clemente Orozco", en Alejo Carpentier. Obras Completas IX. Crónicas 2. Arte, literatura, política (México: Siglo XXI, 1986), 50.

${ }^{36}$ Carpentier, "Diego Rivera, pintor mexicano", en Alejo Carpentier, 46.

${ }^{37}$ Carpentier, "Creadores de hoy...", 51.

${ }^{38}$ América. Magazine Mensual. Órgano de la Liga de Escritores de América, núm. 1 (febrero de 1926).
} 
En su declaración programática, que otorga al libro la base de acción ("el libro realizará esa obra"), concluye con algunas referencias que remiten directamente a investigaciones paralelas del pintor, dedicadas al estudio de los recursos naturales y las capacidades cerebrales, temáticas a las que dedicará textos y monografías exclusivas. Como en otras ocasiones, el artista se valió de reimpresiones, ${ }^{39}$ en este caso fotos, textos y fragmentos de artículos para generar un contenido coincidente con las expectativas del programa.

La revista expone una serie de títulos publicados bajo su sello editorial, textos coincidentes con la expectativa del proyecto y que fueron escritos por los miembros de la Liga. Entre ellos se encuentran Arriba! Arriba!, del mismo Dr. Atl; Vida de Miguel Hidalgo y Costilla de Luis Castillo Ledón y La raza nueva de José R. Benítez, historiador con quien Atl y Manuel Toussaint (1890-1955) colaboraron para la investigación del libro Las iglesias de México (1925).40

Después de la presentación de la revista, el director expone los orígenes del grupo que la coordina, según consigna el artículo "Antecedentes de la Liga de Escritores de América". La organización de la revista -a través de comunicados variados escritos por Atl- es completada con recortes y fragmentos que dieron presencia a colaboradores estratégicos, como es el caso de Alejandro Sux (1888-1959), seudónimo de Alejandro José Maudet. ${ }^{41}$

\footnotetext{
${ }^{39}$ Romero, "Anarchism and Visual Culture...", 22.

${ }^{40}$ La revista se refiere a la biografía en dos tomos que elaboró Luis Castillo Ledón. El historiador mexicano inició esta investigación al tiempo que comenzó su colaboración en el Museo Nacional de Arqueología, Etnografía e Historia. Castillo Ledón fue comisionado en las postrimerías del Porfiriato por la Secretaría de Instrucción Pública, momento a partir del cual comenzó un rastreo minucioso de fuentes y un estudio de la ruta del prócer antes y después del Grito de Dolores. Sin embargo, la empresa fue interrumpida por la Revolución y las modificaciones hechas a la institución en 1917. Finalmente, su obra se publicó post mortem por órdenes del presidente Manuel Ávila Camacho, entre 1948 y 1949 en los Talleres Gráficos de la Nación. Tal vez el libro al que América hace referencia sea un avance de tan amplia investigación. Luis Castillo Ledón, Hidalgo. La vida de un héroe, t. 1 (México: INEHRM / Gobierno del Estado de Hidalgo, 2008). En el caso de José R. Benítez, parece que también se trataba de una obra en preparación, ya que no hay registro de un libro exclusivo sobre el tema de la raza.

${ }^{41}$ Es importante hacer un breve recuento biográfico de Alejandro Sux, figura relevante tanto en la historia de los impresos ligados a la prensa anarquista como en el desarrollo de la vanguardia mexicana, pero poco conocido y apenas trabajado. Poeta, narrador, periodista y anarquista argentino, exiliado en Uruguay, España, México y Francia. Fundador de publicaciones periódicas como Germen. Revista Mensual de Sociología (1906) y La Ilustración Andina. Autor de los poemarios De mi yunque (Cantos al pueblo) (1906) y Cantos de rebelión (1909), de la novela por entregas Bohemia revolucionaria (1910), al igual
} 
De esta manera, Atl buscó demostrar que la Liga tuvo sus antecedentes en el París de inicios de siglo. A través de un texto escrito en Puebla, titulado "Una lucha literaria de París que renace en México", publicado inicialmente en El Universal (febrero de 1926), como respuesta al recibimiento del primer número de América, Sux reafirmó la historia y relevancia de la Liga, así como su apoyo total a la iniciativa de Atl, con un claro tono nostálgico: "Con 'América' en la mano y el cielo en los ojos, hice un viaje hasta la opalina Lutecia, donde hace catorce años, este mismo Atl y yo, creamos, por primera vez, el Movimiento Internacionalista Intelectual que vuelve a renacer en México, tierra de todas las iniciativas...". ${ }^{42}$

El relato de Sux reitera la relevancia de los proyectos editoriales de vanguardia, y no duda en subrayar su condición de guía para la acción bélica o revolucionaria, ya que L'Action d'Art, donde colaboraron ambos autores, y la revista Ariel, dirigida por el escritor argentino, tuvieron como salida directa el campo de batalla, ya fuera la Revolución mexicana, para el caso del artista mexicano, - la causa aliada, para el escritor argentino. Otro aspecto que confirma el comentario de Sux es la idea de unión y complicidad entre proyectos editoriales.

Con un tono parecido al de Atl, donde la modificación o exageración de los hechos parece una constante (por ejemplo, al enfatizar que fueron Atl y Sux los fundadores de la revista L'Action d'Art, y quienes convocaron a los demás integrantes), el autor confirma que la Liga Internacional de Escritores y Artistas tenía como función principal producir revistas en puntos estratégicos, con los cuales estarían en coordinación:

Y un día, no sé cómo, en la modesta imprenta del italiano Salivetti, en un barrio de apaches, nos encontramos: Antonio Bernardo, el Dr. Atl, Fernán Félix de Amador, Zérega Fombona, Ricardo Pérez Alfonseca, André Colomer, Paul Dermée... ¡no sé cuántos más! Y tampoco sé cómo quedó fundada la LIGA INTERNACIONAL DE ESCRITORES Y ARTISTAS, con un órgano de lucha y propaganda en castellano: ARIEL, y dos en francés: L'ACTION D'ART que se publica en París, y EN MARGE, que se editaba en Bruselas. ${ }^{43}$

que de los libros de crónica y ensayo Lo que se ignora de la guerra (1915), Curiosidades de la guerra (1917) y Los voluntarios de la libertad (1918). Alfredo Bojórquez, "Cultura literaria. En la segunda etapa de ¡Luz! (1917-1918)" (tesis de maestría, Colegio de Letras Mexicanas, 2019).

${ }^{42}$ América, núm. 3 (marzo de 1926).

${ }^{43}$ Estos vínculos entre revistas, a decir de Sux, fueron completados por el apoyo de otra serie de proyectos, como el periódico del Boulevard Saint Michel, Le Loup, o el Manchester Guardian en Inglaterra. También destaca el impacto en la prensa, el alboroto en las calles 
Después de dar una larga lista de personajes adscritos a la causa, Sux concluye con dos ideas fundamentales, en las cuales se reconoce el enfoque anarquista-individualista que caracterizó a L'Action d'Art: que la unión entre intelectuales a partir de la edición representa una coalición de lucha, y que el objetivo de estas labores era "abrir las puertas de la libertad individual", en contra de la mentira, la fealdad, la rutina, la tiranía y la explicación. Esta reivindicación del libro y su posibilidad transformadora remite claramente al pasado anarquista, tanto del Dr. Atl como de su camarada.

\section{Un magazine americano}

La revista América. Órgano de la Liga de Escritores de América expresa un momento determinante en la trayectoria editorial, artística y política del Dr. Atl. En ella, el artista reunió diversos intereses en desarrollo, centrados en tópicos como el arte popular, el estudio de la arquitectura, la pintura infantil y el tema de la raza, que Atl expuso en monografías y revistas paralelas. ${ }^{44}$

América representa un punto de inflexión, al operar como un dispositivo -ya lo veremos más adelante- que permitió a Atl recuperar diversos elementos (tácticos y estéticos) de procesos anteriores, al igual que reafirmar otros aportes. Estas actualizaciones de formas de trabajo previas y la introducción a nuevos acercamientos respondieron a una coyuntura política específica.

Antonia Viu destaca las implicaciones del formato del magazine a través del estudio de la materialidad de los impresos, al operar como artefactos y tecnologías capaces de afectar "nuestras formas de atención y los regímenes de percepción". Gracias al uso de textos, fotografías, ilustraciones, recortes, carteles, anuncios, espacios en blanco, listas, tipografías, estos medios son capaces de incorporar o adaptar lenguajes e imaginarios a nuevos formatos. Viu describe las características del magazine como un almacén por su carácter miscelá-

de París ante sus hazañas como grupo y una posible colaboración de Amadeo Modigliani y Filippo Marinetti, quienes esperaban llevar a Italia el llamado de la Liga, "Atl y yo nos abrazábamos, llorábamos de la emoción", ibid.

${ }^{44}$ Entre esas publicaciones destacan los repertorios y estudios sobre el arte popular y colonial en México, pues darán una pauta fundamental para el desarrollo de la política cultural de la posrevolución, y una línea estética que analizaremos. Dr. Atl, Las artes populares (México: Cvltvra, 1921); Dr. Atl, Las artes populares en México (México: s. e., 1922); Dr. Atl, Manuel Toussaint y José R. Benítez, Las iglesias de México (México: Secretaría de Hacienda, 1924). 
neo, al explorar el caso de Zig-Zag de Chile, ya que "tensiona la racionalidad modernizadora del periodo". ${ }^{45}$

Se trata de un tipo de periódico ilustrado organizado en varias secciones que mezclan crónicas, entrevistas, reportajes de actualidad, cuentos, poemas, viñetas, ilustraciones y publicidad. De acuerdo con la autora, la elección y definición de estas secciones constituyen mediaciones para un público en construcción, además de la regulación de cierto contenido. ${ }^{46}$ En ese sentido coincide con la propuesta de Geraldine Rogers al pensar en la revista como una vitrina de objetos que conlleva prácticas de consumo y formas de clasificación. ${ }^{47}$ Estos dos análisis permiten dar sentido a la descripción que el artista realizó sobre la revista, al definirla como un anuncio publicitario que pretendió "conquistar el mercado americano": 48 "El anuncio y solo el anuncio introducirá al libro en todas las clases sociales. Hay que anunciar el libro como se anuncia un nuevo producto comercial, un automóvil o una marca de cerveza".49

El número 1 de la revista América apareció el 1o. de enero de 1926, producida en la calle Guatemala 47 de la Ciudad de México. Como describen Rebeca Barquera y Andrea García, formó parte de las publicaciones elaboradas con apoyo del sello Cvltvra, a través de por lo menos cinco números..$^{50}$ Tuvo un costo de 20 centavos la edición regular y 2 pesos los números de lujo, ${ }^{51}$ estaba compuesta por 32 páginas con texto e ilustraciones. ${ }^{52}$ Las listas de precios incluyeron la posibilidad de envío y la información de cambio a dólar (2.5 pesos), debido al interés de distribución internacional. Como parte de una promoción inicial, el primer ejemplar fue gratuito.

\footnotetext{
${ }^{45}$ Antonia Viu, Materialidades de lo impreso: revistas latinoamericanas (1910-1950) (Santiago de Chile: Metales Pesados, 2019), 23.

46 lbid. 18.

${ }^{47}$ Geraldine Rogers, "Las revistas como dispositivos de exhibición", en Revistas, archivo y exposición: Publicaciones periódicas argentinas del siglo XX, ed. de Verónica Delgado y Geraldine Rogers (La Plata: Universidad Nacional de La Plata, Facultad de Humanidades y Ciencias de la Educación, 2019), 11-19.

${ }^{48}$ Dr. Atl, "Concreciones", América. núm. 1 (febrero de 1926).

49 lbid.

${ }^{50}$ En sus memorias, el Dr. Atl aseguró que llegó a publicar por lo menos 20 números, pero este dato no coincide, hasta el momento, con los números hallados por la autora y diversos especialistas. Puede corresponder al tipo de invenciones o exageraciones características del pintor.

${ }^{51}$ Rebeca Barquera y Andrea García, "Páginas de acción continental. La revista América del Dr. Atl", Reflexiones Marginales, núm. 51 (2019).

52 Sáenz, El símbolo y la acción, 407.
} 
La portada inicial, como en todos los números, es autoría de Atl. La ilustración anuncia el proyecto general de la revista. Destaca la calidad casi artesanal de su producción, al estar resuelta mediante un dibujo acuarelado con agregados de trazos a color y una tipografía caligráfica en tinta negra sobre un recuadro blanco. Los tonos de la imagen van de una gama fría a la base primaria. La composición, a base de yuxtaposiciones de capas, interpreta la propuesta de síntesis estética transhistórica expuesta al interior del ejemplar.

Atl recurre al género del paisaje mediante superposición de planos para unir la naturaleza a la arquitectura prehispánica, colonial y moderna, teniendo como base un espectro del arcoíris y planos de color que surgen desde el subsuelo y la tierra. Este referente cromático revela las fuentes de su pensamiento, que combinan un modelo científico y filosófico..$^{53}$ La ilustración es capaz de reunir las distintas investigaciones y disciplinas vinculadas al artista: geología, mineralogía, cerebrología, el estudio del color, la investigación sobre las artes nacionales y el urbanismo. Gracias a una cualidad reproductible y resolución plástica (dedicada a afectar el ojo y el cerebro), esta propuesta estética pretendió ser difundida por las ciudades americanas.

Como explica Rebeca Barquera, el Dr. Atl era un pintor-alquimista centrado en la experimentación material. Barquera demuestra cómo la pintura de Atl funciona por medio de la superposición de estratos, a manera de capa geológica. Con ayuda del "atlcolor", un crayón inventado por el pintor y producido a base de pigmentos y aglutinantes (resinas, ceras, aceites y derivados del petróleo), ${ }^{54}$ diseñó un método pictórico (esencialmente paisajístico, material y simbólico) destinado a la creación de volúmenes y de vibraciones lumínicas, con el objetivo de evocar el funcionamiento del universo. Esta resolución revela que para Atl cada partícula de la naturaleza debía estar integrada y redirigida mediante la belleza y la potencia -muy en el tono d'annunziano-, 55 en un "plan de acción" que tomó en cuenta desde la escala celular hasta la estelar: "Fuerzas extrañas han extraído de la oscuridad del subsuelo del Nuevo Continente el oro

\footnotetext{
${ }^{53}$ Renato González Mello, "El Dr. Atl. El arcoiris y los fabricantes de células", en Vanguardia y experimentación en México, 1910-1950, ed. de Renato González Mello y Anthony Stanton (México: Museo Nacional de Arte, 2013), 93-99.

${ }^{54}$ Rebeca Barquera, "Los atlcolors de Dr. Atl en las obras más representativas del Museo Nacional de Arte", Museo Nacional de Arte, 17 de mayo de 2021, acceso el 15 de julio de 2021, https://www.facebook.com/watch/?extid=SEO----\&v=248348717070785.

${ }^{5}$ Sánchez Rodríguez, "Il Superuomo ed Energeia...".
} 
y el petróleo - nosotros haremos brotar de las concavidades del cerebro de las gentes de América la luz que ha de ir iluminando una por una la conciencia de los olvidados". ${ }^{56}$

El discurso americanista expuesto en las páginas de la revista dirigida por Atl respondió a una tendencia política con gran auge en el continente, entre 1926 y 1930. A mediados de 1920 el antiimperialismo incluyó nuevos repertorios a la herencia del arielismo y una actualización del legado intelectual de José Martí, ante la incorporación de referentes marxistas, el peso de los movimientos estudiantiles y la defensa sandinista como tema fundamental. ${ }^{57}$ El tono de las páginas iniciales reafirma el objetivo de proyectar un programa político y cultural dirigido a todo el hemisferio: "de Alaska a Cabo de Hornos".

El vínculo con Amauta (1926-1930) de José Carlos Mariátegui reafirma este propósito, acción evidente en el intercambio entre América y Amauta a través del artículo "Cinemática", de Atl, pero también en la coincidencia de ciertos temas (indigenismo, arte popular, arte de vanguardia). Tanto Atl como Mariátegui tuvieron como propósito general de sus proyectos editoriales (aunque cada uno con modelos propios) crear alternativas políticas y "revolucionarias" en sus propios contextos, al tiempo que buscaron generar coaliciones regionales para confrontar el avance del imperialismo. ${ }^{58}$

Los directorios denominados "Los Comités de las Liga de Escritores de América en el Continente", publicados en los números 3 y 4-5, exhiben los esfuerzos para crear redes y contactos en puntos vitales como Cuba (en mayor medida), Honduras, Costa Rica y Argentina, al igual que alianzas con colegas, tales como Alejo Carpentier, Jorge Mañach, Juan Marinello, Luis Quintanilla, Max Henríquez Ureña, Joaquín García Monge. Llama la atención la concentración de los Comités en Centroamérica y El Caribe, acción de enlace que confirmó la

\footnotetext{
${ }^{56}$ Dr. Atl, "Proclama", América, núm. 1 (febrero de 1926).

57 Yankelevich, Miradas australes, 312. Algunas de las figuras que encabezaron esta tendencia desde Latinoamérica fueron Julio Antonio Mella, Víctor Raúl Haya de la Torre, Diego Rivera y José Carlos Mariátegui, quienes dialogaron, aliaron, debatieron y separaron en momentos determinantes del avance de la causa y tuvieron un papel relevante en las publicaciones dedicadas al tema, acompañadas por participaciones en congresos y diversas acciones políticas.

${ }^{58}$ Dr. Atl, "Cinemática mexicana", Amauta. Revista Mensual de Cultura (noviembre de 1926) y América, núm. 1 (febrero de 1926). Natalia de la Rosa, "Aesthetic Constructions of Latin American Reality. Avant-Garde Dialogues Between Mexico and Peru, 1926-1930", en Majluf y Adams, Redes de vanguardia, 150-163.
} 
labor de conexión hecha por el escritor yucateco Luis Rosado Vega (1873-1958), una suerte de corresponsal de la Liga por estos lugares. ${ }^{59}$

La insistencia de Atl en conseguir aliados se refleja en el apoyo que la revista Horizonte, del grupo estridentista, le ofreció al publicar en su primer número de abril de 1926 la proclama de la Liga de Escritores. ${ }^{60}$ Para el pintor, la conformación y unión de dichos comités daría cauce a la formación de "una nueva clase" -la aristocracia americana-, encargada de velar por los intereses continentales.

El segundo número de América mantiene la factura artesanal, aunque comienza a haber inclusiones de elementos tecnológicos incipientes, como el uso del stencil en la portada, que sustituye la referencia al paisaje lumínico por un diseño inspirado en el ollin, compuesto a manera de logo. Continúa la letra cursiva, utilizada para señalar exclusivamente el título de la publicación, la adscripción a la Liga y el número de edición. Rebeca Barquera y Andrea García realizan una comparativa entre los logos del grupo "Acción de arte", expuestos en símbolos que expresan la frase "Crear la fuerza", propuestos para una exhibición de 1921 en la Escuela Nacional de Bellas Artes. ${ }^{61}$ Las autoras insisten en destacar este diseño como antecedente en la resolución gráfica y tipográfica de América, especialmente en la inspiración "neoprehispánica", basada en el glifo del ollin de la Piedra del Sol. ${ }^{62}$

Al interior, la organización de la revista cambia y agrega el precio de los ejemplares y números especiales. Inicia la inclusión de publicidad, a partir del anuncio de El Renacimiento en la hoja de créditos, una tienda dedicada a materiales para artistas. En este mismo número se imprimió como contraportada la caricatura Mulas más piores me han echado (ca. 1926) de José Clemente Orozco, acción que sirvió a Atl para reiterar que América tenía un vínculo con aquellas propuestas revolucionarias desarrolladas ante nuevas circunstancias. Orozco es el artista con mayor representación en América a través de esta caricatura, o por medio de la obra mural Omnisciencia (1925) y la pintura Soldados y

\footnotetext{
59 Una breve nota da cuenta de la misión de Rosado Vega por "Cuba, Las Antillas y América Central". Entre sus propósitos más urgentes estaba la participación en un congreso de periodistas en Washington y la fundación de Comités en Estados Unidos y Canadá. "La labor de Luis Rosado Vega", América, núm. 3 (marzo de 1926).

60 "PROCLAMA del comité ORGANIZADOR de la LIGA de Escritores de AMÉRICA", Horizonte, núm. 1 (abril de 1926).

${ }^{61}$ Barquera y García, "Páginas de acción continental...".

${ }^{62} \mathrm{lbid}$.
} 
soldaderas (1926). Atl no dudó en reiterar que Orozco era el ejemplo del "artista revolucionario".

No cabe duda de que la elección de este modelo editorial responde a dos confrontaciones de corte antiimperialista. Por un lado, expresa una resistencia que no reside solamente en lo que publica como contenido, sino en la misma elección de un formato que se apropia de un patrón característico de la prensa norteamericana. Con ello pretende contrarrestar una intervención económica al usar sus mismas herramientas. Por otra parte, reitera un sentido antihispanista, al proponer bloques solidarios (comités) por todo el continente que representaran una confrontación abierta frente al mercado internacional, la intervención imperial y la herencia colonial, donde la defensa de la lengua era primordial ("no somos escritores ibero-americanos, somos escritores americanos").

En cuanto a las colaboraciones, el contenido de todos los números reitera el propósito de difusión intercontinental, como lo ejemplifica un artículo de opinión de corte antiimperialista presente en un segundo número. El recorte "Acción contra el usurpador de Nicaragua", dedicado a denunciar el régimen del general Emiliano Chamorro y sus planes de concesión extranjera, fue firmado por el Dr. Atl como presidente de la Liga y Alejandro Sux como representante de "La Patria Grande", en alianza con el Comité Patriótico Nicaragüense, representado por Pedro José Zepeda, embajador de Nicaragua en México, y el general S. Sedilles. Al texto se le da total relevancia, ya que abre la edición y está acompañado, en su segunda página, por un anuncio del Banco de México que abarca la mitad de la hoja. Con este gesto, el editor pretendió dar validez, peso y respaldo al comunicado.

Desde los años de residencia en Europa, Atl reconoció que los impresos eran vehículos con una función específica. Por ejemplo, a partir de La Révolution au Mexique buscó generar un órgano de difusión para la causa carrancista en Europa; o por medio de La Vanguardia, diseñó -teniendo en mente la intervención norteamericana en Veracruz de 1914- una campaña de propaganda para las tropas, al tiempo que activó un modelo de mediación entre el Constitucionalismo y la Casa del Obrero Mundial. ${ }^{63}$ En 1926 Atl preparó un magazine que se alejó de la sátira, la caricatura, las reseñas de teatro, las secciones de crítica, y cedió el paso a un "dispositivo de exhibición" que procuró la formación de un nuevo lector. ${ }^{64}$

\footnotetext{
${ }^{63}$ Romero, "Anarchism and Visual Culture...", 26.

${ }^{64}$ Rogers, "Las revistas como dispositivos de exhibición", 15.
} 
La revista América -imaginario político y artefacto funcional- vinculó la geografía, la lingüística, la etnografía y la pedagogía con el fin de quebrar un orden (o sistema mundo) imperial-colonial. ${ }^{65}$ Dicha apuesta tuvo como fin último compartir esta propuesta por todo el hemisferio y dar forma a intercambios teóricos, simbólicos y materiales sustentados en las publicaciones y la lengua.

Pueden reconocerse en los números iniciales textos explicativos, la mayoría de ellos redactados por el Dr. Atl, ya fuera porque respondió a un control total sobre la organización de la publicación, o bien a una producción urgente, con escasos recursos y seguidores. Estos documentos corresponden a proclamas, miradas retrospectivas y artículos reivindicadores de la causa e historia de la Liga de Escritores, ${ }^{66}$ a través de distintas voces que respondieron al llamado del primer número, como fue el caso de Sux, o por el seguimiento hecho a las actividades de los miembros de la Liga, como sucedió con Rosendo Salazar y Luis Rosado Vega. ${ }^{67}$ Dichos artículos son acompañados por una reedición y adaptación de investigaciones hechas por Atl, que dan forma a su programa económico-estético, dedicadas al arte popular, la pintura, la pedagogía artística y el urbanismo, y sostienen el proyecto lingüístico de la revista.

El armado de los ejemplares fue estructurado a partir de un propósito específico, dedicado a contrarrestar el avance de la política oficial: "nos dedicamos a pensar, a dar conferencias y a propagar nuestras ideas en la prensa, pero como en los periódicos no podíamos expresarnos libremente fundamos una revista -América-, que a los dos números alcanzó una gran circulación".68 Se trata, por tanto, de un modelo editorial de propaganda, y es, al mismo tiempo, un difusor capaz de disputar o contrarrestar un canon en construcción, basado en lo que Att llamó la "expansión comunista".69

${ }^{65}$ Immanuel Wallerstein, World-System Analysis: An Introduction (Durham: Duke University Press, 2004).

${ }^{66}$ La presentación del programa y de la Liga de Escritores y Artistas de América estuvo compuesta por: una lista de publicaciones de la organización, una nota de presentación, los antecedentes de la Liga, un manifiesto (proclama) firmado por el Comité Central Organizador; complementa esta serie de textos un programa estético definido como "síntesis plásticas mexicanas", una nota aclaratoria sobre el formato de publicación, "Concreciones", y un artículo del Dr. Atl titulado "Cinemática mexicana", que funcionó como comentario crítico a la Revolución y contrapropuesta al avance institucional del movimiento.

67 "Un Congreso de Escritores Latinoamericano (La Prensa, Buenos Aires)", América, núms. 4-5 (abril-mayo de 1926) y "Nuestras grandes publicaciones. México en pensamiento y acción", ibid., núm. 3 (marzo de 1926).

${ }^{68} \mathrm{Dr}$. Atl, Gentes profanas del convento, 214.

${ }^{69}$ Ibid., 216. 
El número 3 es el ejemplar que resulta más completo y expone los ejemplos literarios que representan el ideario de la publicación. La portada presenta un cambio sustancial, al reorganizar el acomodo de la página ceñido al diseño de la caligrafía. Esta ilustración expone un logo que une un sentido colorístico-espectral con la referencia arqueológica. De tal manera, el artista construye un símbolo que reafirma el sentido de la revista, mediante un volcán ligado como pictograma del ollin y como título, al crear un símbolo que reitera el sentido geográfico (topográfico) del proyecto: "La Liga de Escritores de América es tan americana como el Chimborazo, el Popocatépetl o el Monte San Elías". Como variante del logo "Crear la acción", esta representación complejiza la condición del diseño, al funcionar al mismo tiempo en calidad de símbolo e imagen, como síntesis y como palabra, al fusionar todo con un volcán. En cierta forma, la resolución interpreta de forma visual los ejercicios lingüísticos expuestos al interior.

Otra variación fue la inclusión de tipografía mecánica para desglosary demostrar desde la portada un amplio contenido y colaboraciones en la revista, que esta vez sumarán la presencia destacable de la literatura femenina, a partir de los poemas de María del Mar y un cuento de María Luisa Ocampo, a la par de las intervenciones de Alfonso Cravioto y Francisco Monterde, director de la revista Antena (1924). Esta lista se complementa con las colaboraciones literarias de los números 4-5 de Esperanza Velázquez Bringas, Lázaro y Carlo Lozano García, Djed Bórquez (Juan de Dios Bojórquez) y Jaime Torres Bodet, junto a los estudios de Zúñiga, del urbanista Carlos Contreras, del antropólogo Miguel Othón de Mendizábal y la nota crítica sobre el pintor Rufino Tamayo, escrita por Gilberto Owen. La publicación cierra con los fragmentos de los miembros de la Liga: Ocampo (la autora con más intervenciones en la revista), José M. Benítez y Carlos Noriega Hope, director del periódico El Universal Ilustrado.

Los números 4-5 de la revista comprueban, una vez más, la tentativa del programa. El ejemplar, correspondiente a abril y mayo de 1926, exhibe una versión de paisaje simbólico. En esta ocasión la A de América forma una montaña/ volcán que, a la vez, dibuja una cavidad donde posa una figura masculina de corte clasicista y monumental, la cual recuerda los trabajos de Atl en Europa, así como sus primeros ensayos murales en San Pedro y San Pablo. De nueva cuenta, el artículo de apertura remite a un tema internacional, a través de un recorte de La Prensa de Argentina que reseña el Congreso de Escritores Latinoamericanos, en el que Luis Rosado Vega fue partícipe. El recuadro dialoga y tiene el mismo protagonismo que un anuncio de la Compañía Mexicana de Luz. 
Dicho acomodo comprueba el interés de Atl por los temas de corte industrial, ante el propósito de crear o apoyar programas de electrificación e irrigación. ${ }^{70}$

El paisajista explica que el magazine atendió a los procesos de industrialización acelerada en América, específicamente de Estados Unidos. ${ }^{71}$ En mayor medida, la política panamericana e imperialista también provocó reacciones, sobre todo en la segunda mitad de 1920, en contra de las estrategias intervencionistas de Estados Unidos sustentadas en la Doctrina Monroe. Atl explica que el "diario", la publicación que utilizó desde décadas anteriores, es "la síntesis literaria de la vida contemporánea" y "el documento escrito más importante de nuestra vida presente". ${ }^{72}$ Por tanto, siendo la publicación periódica una nueva forma del libro, esta revista era concebida como el libro-diario de la Liga de Escritores de América.

La eficacia que Atl encontró en este nuevo formato se centró en la posibilidad de cohesionar un proyecto comercial, industrial e intelectual para modificar las condiciones desfavorables en torno a la distribución del conocimiento regional, al atacar directamente las estructuras coloniales que operaban en el mercado editorial y en la misma producción del saber..$^{73}$ Así lo expuso el pintor: "No tratamos de imponer una nueva escuela literaria, ni una nueva escuela filosófi-

${ }^{70}$ La revista América evidencia los vínculos con el constitucionalismo. En este desplegado queda expuesto un argumento que vincula ese momento revolucionario -y los remanentes sindicalistas, antimilitaristas y anticlericales- con un nuevo diálogo con el Partido Laborista, aspecto que demuestra un paso de la reforma agraria hacia la proyección industrial, centrada en los temas de irrigación y electrificación. Dr. Atl, "Hay algo profundamente cambiando en México", América, núm. 2 (febrero de 1926).

${ }^{71}$ Un antecedente como Vida Americana (1921), revista fundada en Barcelona por un joven David Alfaro Siqueiros, en colaboración con el poeta y editor anarquista Joan SalvatPapasseit, permite entender la trayectoria y modificaciones al apuntalamiento continental para la vanguardia. También revela, en la elección del título, un intento de definición y apertura geográfica para un proyecto artístico y cultural. El sentido de lo "americano" -en este primer y único número de la publicación- incorporó un discurso de la unión continental y transnacional, de norte a sur, para reafirmar y señalar un proceso de modernización e industrialización acelerado en América, que contrastaba con el ocaso económico que Europa vivió al finalizar la Primera Guerra Mundial. Natalia de la Rosa, "Vida Americana, 1919-1921. Redes conceptuales en torno a un proyecto trans-continental de vanguardia". Artl@s Bulletin 3, núm. 2 (2014): Article 2.

${ }^{72}$ América, núm. 1 (febrero de 1926).

${ }^{73}$ Fernando Garcés V., "Políticas del conocimiento y la colonialidad lingüística y epistémica", en Pensamiento crítico y matriz (de)colonial. Reflexiones latinoamericanas, coord. de Catherine Walsh (Quito, Ecuador: Universidad Andina Simón Bolívar / Abya Yala, 2005), 137-168. 
ca, ni una escuela científica -queremos crear una organización que permita la exposición de los Escritores de América, y que ese pensamiento circule entre todos los pueblos del Continente--".74 El artista evidencia cómo afecta en el mismo grado en un sistema económico colonial una intervención extranjera en el suelo nacional que el control cultural y epistémico:"75 "La confección de un Diccionario Nacional es tan importante como la redacción sobre la ley del Petróleo".76

El ejemplo más radical de este enfoque está en el artículo-anuncio dedicado a presentar, por medio de un texto híbrido, la promoción y reseña del libro de Rosendo Salazar, México en pensamiento y acción (1926), miembro de la Liga y viejo camarada del pintor. Atl pretendió presumir la publicación de libros encargados de difundir los ideales del grupo. El desplegado comparte página con el recorte "La emancipación de la lengua" del poeta Horacio Zúñiga, ${ }_{1}^{77}$ del cual se hablará más adelante, acción que confirma los propósitos señalados. Finalmente, los últimos números presentan ejemplos literarios consecuentes con los ideales de la organización.

\section{Diccionarios regionales y ortografías experimentales}

La particularidad de la revista América como proyecto -a diferencia de publicaciones nacionales anteriores o paralelas, por ejemplo Mexican Folkways (1925-1937), Horizonte (1926-1927) y Forma (1928), con las cuales comparte preocupaciones como el arte popular, las artes plásticas o la antropología- radica en que la escritura, el libro y el mercado editorial adquieren la base de organización y expectativas del programa. Lo anterior puede constatarse a través de una revisión del esquema de operación y de los propios ejemplares, que desplegaron el repertorio propuesto por Atl en nombre de una colectividad.

El interés mostrado respecto al libro y la palabra fue complementado con una propuesta específica que sostuvo la organización de América, dedicada a concebir un lenguaje nuevo. Esta particularidad vincula dicha revista con otras propuestas literarias y artísticas paralelas de la vanguardia local, que centraron

\footnotetext{
${ }^{74}$ Dr. Atl, "Proclama", América, núm. 1 (febrero de 1926).

${ }^{75}$ Silvia Rivera Cusicanqui, "La raíz: colonizadores y colonizados", en Violencias encubiertas en Bolivia. T. 1, Cultura y Política, ed. de Xavier Albó y Raúl Barrios (La Paz: CipcaAruwiyiri, 1993).

${ }^{76} \mathrm{Dr}$. Atl, "La formación del diccionario mexicano", América, núm. 3 (marzo de 1926).

77 Horacio Zúñiga, "La emancipación de la lengua", América, núm. 3 (marzo de 1926). Publicado originalmente en El Universal, 8 de marzo de 1926.
} 
su experimentación en una reflexión o disputa por la lengua. Ejemplo de ello son: las alteraciones ortográficas que el Grupo Orkopata expuso en el Boletín Titikaka; la generación de repertorios locales como los planteados por Mário de Andrade en la Gramatiquinha da fala brasileira, o por Jorge Luis Borges con el Idioma de los argentinos; o la creación de lenguajes utópicos, como fue la panlengua de Xul Solar. ${ }^{78}$

En ese sentido, el artículo titulado "Cinemática" constituye una síntesis programática y estratégica. Este breve, pero contundente texto funciona para reiterar y resumir las tendencias de América, al tiempo que proporciona una voz directa, a través de las referencias biográficas de Atl como testigo y actor de los recientes acontecimientos políticos nacionales, entre ellos el proceso revolucionario. Se trata de un ejercicio de redundancia discursiva y táctica, en tanto que reitera el uso del dispositivo tecnológico que representa la revista y reafirma su eficacia, al utilizar otra referencia técnica para volver a presentar su programa por medio del cine. ${ }^{79}$

Atl remite al uso de imágenes dinámicas que permiten exhibir una panorámica del contexto nacional (el movimiento armado, el gobierno revolucionario, el estatuto del país, las organizaciones obreras) y con ello ofrece una alternativa de acción a través de la propuesta que representa América. Es decir, por medio de la escritura y la difusión de la producción cultural desarrollada en México conformaba una "coalición de combate", representada por la Liga de Escritores y su publicación.

Bajo el esquema del programa político de América, el formato de diccionario y la consolidación de un nuevo repertorio lingüístico constituyeron la línea general y de desarrollo del proyecto. El estudio sistemático de la revista evidencia que el discurso construido alrededor de esta propuesta funciona como la estructura de la edición: la presentación del programa insiste en esa idea, mientras el desarrollo introduce textos que confirman dicha apreciación.

En cada uno de los 5 ejemplares existe una intervención dedicada al proyecto de diccionarios y de estudio de la lengua. El programa plantea de forma general el problema y no será sino hasta el segundo número cuando introduce el tema con el texto "Proponemos la formación de un diccionario mexicano", publicado sin firma y a manera de llamamiento e invitación; el tercer número presenta la "Formación del diccionario mexicano", del Dr. Atl, y "La

\footnotetext{
${ }^{78}$ Schwartz, Las vanguardias latinoamericanas, 64.

79 Rogers, "Las revistas como dispositivos de exhibición", 11-19.
} 
emancipación de la lengua", de Horacio Zúñiga; por último, el proyecto concluye con los ejemplares 4 y 5 mediante una amplia descripción del tema por parte del lingüista y profesor de pintura Delfino Torijano.

Este conjunto consolida una de las líneas más destacadas en América. Los dos primeros textos funcionan a manera de invitación y exhorto por parte del mismo Atl, quien señaló qué objetivos buscaba alcanzar con esta intervención y los posibles colaboradores de la causa, mientras que los dos artículos más importantes y representativos de la propuesta corresponden a Horacio Zúñiga y Delfino Torijano.

En el caso del escritor toluqueño, el texto impreso en la revista corresponde a una respuesta que el autor preparó a la convocatoria de Atl desde las páginas de la publicación. Zúñiga atendió de inmediato al llamado del pintor y de la Liga por considerar primordial la labor de definición de "nuestro fenómeno lingüístico", en contraposición a las reglas y guías dictadas desde España, y a manera de una proyección futura. Los trabajos del poeta, orador, novelista y crítico en espacios como el Instituto Científico Literario de Toluca y en la redacción de sus trabajos históricos y educativos, dieron la pauta para ofrecer un comentario ante tal provocación.

Dicho cuestionamiento obligó a los autores a poner en perspectiva diversos aspectos que quedaron abiertos o irresueltos. El análisis en torno a la vigencia y permanencia del castellano como lengua oficial o representativa nacional obligó a pensar tanto en lazos como en separaciones urgentes: "nadie niega que España es la madre común de todas las músicas del verbo hispano; nadie niega que las quillas de las carabelas pautaron de asombros el océano para que escribieran misioneros y conquistadores". ${ }^{80}$

En estas reflexiones Zúñiga, con la mirada histórico-didáctica que lo caracteriza, dio continuidad al debate que autores como Melchor Ocampo, Domingo Faustino Sarmiento y, particularmente, Andrés Bello ${ }^{81}$ expusieron en debates transnacionales sobre las ortografías locales, en el contexto de la construcción de los nacionalismos regionales durante el siglo XIX.

\footnotetext{
80 Zúñiga, "La emancipación de la lengua". También publicado en Jorge Olvera García, coord., Ensayo. Colección Horacio Zúñiga. La luz del conocimiento, t. VI (Estado de México: UAEM, 2016), 89-92.

${ }^{81}$ Las obras del venezolano Andrés Bello dedicadas a la ortografía fueron publicadas en Londres y tuvieron un impacto importante en América: Indicaciones sobre la conveniencia de simplificar i informar la ortografía en América y la famosa Gramática castellana destinada a los usos americanos, ambas de 1823.
} 
Al tomar en cuenta las coincidencias que las naciones hispanoamericanas compartían respecto a la lengua, así como aspectos históricos, más que etimológicos, o el cambio de las reglas a "como se hablaba" o con una "omnipresencia del sonido", estos personajes buscaron poner en diálogo las formas del habla que podrían unir al continente, al tiempo que señalaron separaciones claras frente a España: "A pronunciación diferente, observan, diferente ortografía; a una nueva situación política, una nueva ortografía". ${ }^{82}$

El artículo titulado "La emancipación de la lengua", de Horacio Zúñiga, tiene como principal argumento que aunque la Metrópoli haya dado las bases de la lengua, no debía regir más las condiciones y transformaciones constantes: "España no puede, no podrá acaso nunca, a pesar de sus indiscutibles excelencias, regir eficazmente el proceso de una lengua que es nuestra ya, que a nosotros y sólo nosotros toca corregir, robustecer, afinar e iluminar".83

De esta manera, las consignas expuestas con la lírica que caracteriza a Zúñiga en "La emancipación de la lengua", toman forma:

¿Que no es lo mismo que otra? Ciertamente, como que la emancipación de la conciencia colectiva es mucho más importante que la emancipación político-social. Pero, precisamente porque aquélla es de más significación que ésta y precisamente porque tal emancipación es un HECHO consumado a través del siglo que llevamos de vivir políticamente alejados de España, sufriendo influencias sociales, intelectuales y materiales más fuertes que las de España (las de Francia y Estados Unidos, por ejemplo), por eso y sólo por eso, si se quiere desatender a otras muchas razones de la misma fuerza, ya es tiempo de que, sin dejar de ser españoles en la médula de nuestra psiquis (¿no seguimos creyendo, no seguimos cantando y orando como España?). ${ }^{84}$

La paradoja que no deja resuelta el texto del escritor de La universidad, la juventud, la revolución, es la que surge ante el reclamo de una atención del centro y el llamado a una autonomía de las colonias.

\footnotetext{
${ }^{82}$ Miguel Rodríguez, "'Coincidencias': la ortografía en la construcción de las naciones hispanoamericanas", Secuencias, núm. 54 (septiembre-diciembre de 2002): 68, acceso el 25 de marzo de 2021, http://dx.doi.org/10.18234/secuencia.v0i54.788.

${ }^{83}$ Zúñiga, "La emancipación de la lengua", 90.

84 Ibid., 92.
} 
Por otra parte, la colaboración de Delfino Torijano cierra, de alguna forma, el proyecto de la revista América. No sólo representa la última presentación de algún tema en el breve proyecto del Dr. Atl, sino que también -por el acomodo de su artículo- reafirma su relevancia, al estar acompañado por el "Directorio americano", que demostraba el apoyo de las redes de intelectuales, y por la carta de Atl a Puig Casauranc, en la que expuso la iniciativa del "Diccionario mexicano".

Por tanto, la aproximación de Torijano al tema referente a los diccionarios y ortografías locales resultó un elemento contundente para el programa del magazine, y por ello este texto tiene un desarrollo más amplio que la mayoría de las colaboraciones. Cabe destacar que la elección de Torijano también fue estratégica, debido a que tenía un papel determinante, desde varias décadas atrás y hasta ese momento, en el contexto de la enseñanza de la pintura y la redacción de manuales oficiales de gramática, tanto para las oficinas de Instrucción Pública como para la Secretaría de Educación.

A través de "La unigrafía de la lengua" el autor propone un camino concreto, a diferencia de Zúñiga, que mantiene el tema en el ámbito de la reflexión. Torijano enlista los puntos que considera necesarios para llevar a cabo la empresa $y$, tras detenerse brevemente en explicar los propósitos de una "emancipación" nacional y continental, da paso a las modificaciones requeridas ante una nueva realidad "intelectual, racial e independiente" que pretende unificar la raza al unificar la lengua, al incorporar las "voces genuinas" y "vocablos exóti$\cos ^{\prime \prime}$ que respetarán la génesis del fonema. Como sucedió con propuestas anteriores, esta solución da relevancia al sonido y las posibles variaciones, más que a la etimología: "así multiplicaremos los sonidos y las voces y haremos de nuestra lengua, el idioma más rico y más sonoro del mundo". 85

La otra alternativa era el estudio de los signos gráficos para llevar este proceso al acto de la lectura, "la fijeza del signo en su representación fonológica es de suma importancia para la escritura correcta de la lengua y para facilitar su inmediata traducción al leer". ${ }^{86}$ Este acercamiento es de un corte biologicista casi lamarckiano, ${ }^{87}$ ya que enfatiza las variaciones del "sistema articulatorio del

${ }^{85}$ Delfino Torijano, "La unigrafía de la lengua", América, núms. 4-5 (mayo-junio de 1926).

${ }^{86} \mathrm{lbid}$.

${ }^{87}$ El lamarckismo remite a aquella propuesta evolutiva expuesta por Jean Baptiste Lamarck en la Filosofía Zoológica (1809). Se caracteriza por señalar el medio y el clima como elementos sustanciales para los cambios biológicos. En México, y especialmente en el caIlismo, tuvo una fuerte presencia entre los médicos y pedagogos. Renato González Mello 
habla" y de "la etnogenia" dependiente del impacto climático, con énfasis, de nueva cuenta, en los vínculos entre el signo oral y el gráfico, expuestos ya en su "Ortografía de la Lenwa Latino-amerikana".

Como explicamos, la revista puso especial énfasis en el sentido mercantil y pedagógico, como puntos necesarios para contrarrestar las desventajas culturales imperialistas. No obstante, para comprender el sustento formativo y educativo del diccionario es necesario atender al perfil indigenista que sostiene la apuesta. Los escritos en torno al arte popular, la arquitectura mexicana, la pedagogía artística y, por supuesto, la lengua, están sustentados en un proyecto indigenista en claro diálogo con autores cercanos al pintor, como Manuel Gamio, Othón de Mendizábal y Castillo Ledón.

Ejemplo de ello es la introducción en América de la sección "Concursos", en las últimas páginas de la revista. Se trata de una estrategia pedagógica y participativa, para lectores adultos y niños, que invitaba al envío de pinturas de paisajes, cuentos y anécdotas de la Revolución. Estas invitaciones no eran sino una tentativa de expansión del programa pedagógico-estético y médico-higienista de las escuelas al aire libre. ${ }^{88}$ En una reseña de la exposición en el Palacio de Minería (1925) sobre los trabajos de los centros populares artísticos, ${ }^{89}$ Atl incorpora una preocupación respecto a la producción pictórica infantil. Ya se habían demostrado, como comprobó la visita y alabanza de Pierre Janet a la empresa, los beneficios psico-fisiológicos y orgánicos para el pupilo de este método de

y Deborah Dorotinsky, eds., Encauzar la mirada. Arquitectura, pedagogía e imágenes en México, 1920-1950 (México: UNAM, IIE, 2010).

${ }^{88}$ Las Escuelas de Pintura al Aire Libre tienen distintas etapas. El antecedente directo fue la de Barbizón, fundada en 1913 por el pintor Alfredo Ramos Martínez en Santa Anita, promotora de las técnicas del impresionismo. La segunda fue fundada también por él a mediados de 1920, en el barrio de Chimalistac, al sur de la capital del país. Posteriormente, como programa vinculado a la Secretaría de Educación Pública, se fundaron sedes en Coyoacán, Churubusco, Xochimilco, Tlalpan y Valle de Guadalupe. El cambio en esta etapa radica en que no será una propuesta para estudiantes de la Academia, sino para poblaciones populares. El perfil pedagógico dialogó con el acercamiento primitivista de la pintura de vanguardia. Laura González Matute, "Proyectos educativos de la posrevolución. Las escuelas al aire libre", Discurso Visual, CENIDIAP, acceso el 17 de julio de 2021, http:// discursovisual.net/dvweb10/agora/agolaura.htm.

89 Dr. Atl, "Prólogo" a Catálogo de la primera exposición de las Escuelas de Pintura al Aire Libre, Palacio de Minería, 22 al 31 de agosto de 1925, Universidad Nacional de México, 1925. 
enseñanza..$^{90}$ El siguiente reto, a decir de Atl, requería encontrar un mercado para estas obras y asegurar la continuación del desarrollo artístico (y racial) de estos niños, quienes "expresan su concepto de vida y exponen sus ideas sobre las cosas de la naturaleza".91

Resulta claro cómo el Dr. Atl integró una serie de estudios arqueológicos, antropológicos y etnográficos a su propio repertorio filosófico y visual. Un propósito primordial para Atl y sus colegas fue el estudiar las "expresiones del pueblo" con el objetivo de una proyección utilitaria y comercial. La "esencia de la raza" resultó una expresión habitual en el análisis de diversas manifestaciones culturales que fueron incorporadas a los repertorios nacionales, al ser definidas como industrias populares o folklore. ${ }^{92}$ Las colecciones, museos, catálogos y revistas funcionaron como mecanismos de clasificación y exhibición para dichos inventarios. Los estudios del pintor sobre arte popular y arquitectura religiosa fueron decisivos para la formación de esta relación.

Como hemos mencionado, la inclusión de los trabajos de Zúñiga y, especialmente, de Torijano indican que el propósito final del proyecto del "Diccionario mexicano" era poner en marcha un programa educativo que incorporaba estas "expresiones raciales" desde el habla, las cuales completaron la base de un ideario que buscó interceder en una serie de aspectos que creía necesarios para llevar a cabo un inabarcable plan de acción. En estos acercamientos, donde impera el tema de la raza, resulta claro el peso del proyecto de mestizaje. Por último, propuestas como la de Torijano promueven una unificación y homogeneización lingüística, que no será dictada por España, pero sí por el Estado. ${ }^{93}$

\footnotetext{
${ }^{90}$ Dr. Atl, "Los niños en las exposiciones públicas de pintura", América, núm. 2 (febrero de 1926).

${ }^{91}$ Ibid. Para el segundo aspecto, el paisajista sugirió crear un programa de pintura mural en escuelas y edificios públicos. Curiosamente, una de las tendencias artísticas más importantes para el callismo y el Maximato será la inclusión de murales en escuelas primarias. González Mello y Dorotinsky, Encauzar la mirada.

92 Francisco Quevedo, "El alma de nuestra raza y el folklore artístico", Revista de Revistas. El Semanario Nacional 7, núm. 323 (julio de 1916).

${ }^{93}$ Yásnaya Elena Aguilar Gil, ¿Nunca más un México sin nosotros? (San Cristóbal de las Casas, Oaxaca: CIDECI-Unitierra Chiapas, 2018).
} 


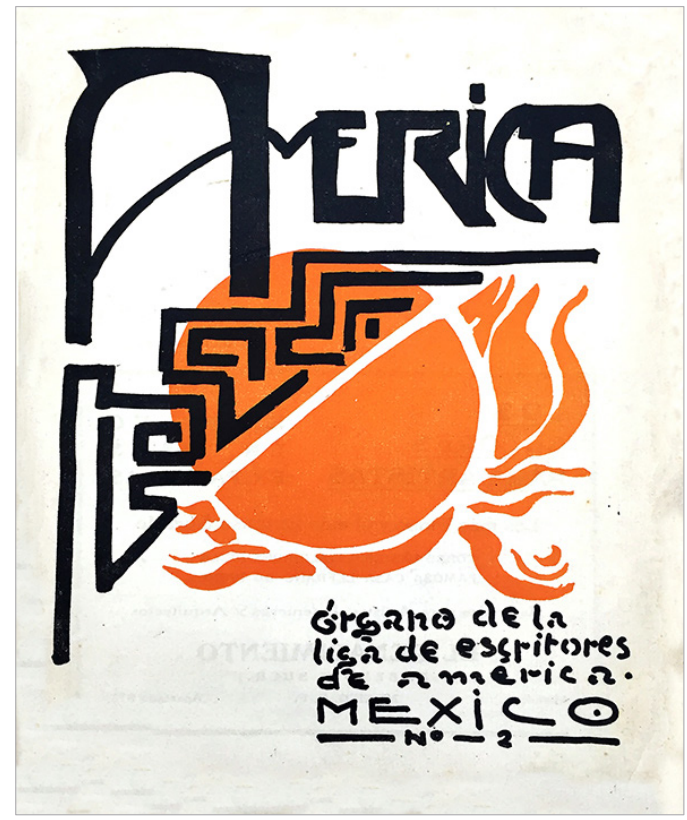

Dr. Atl, portada de la revista América, núm. 2 (febrero de 1926).

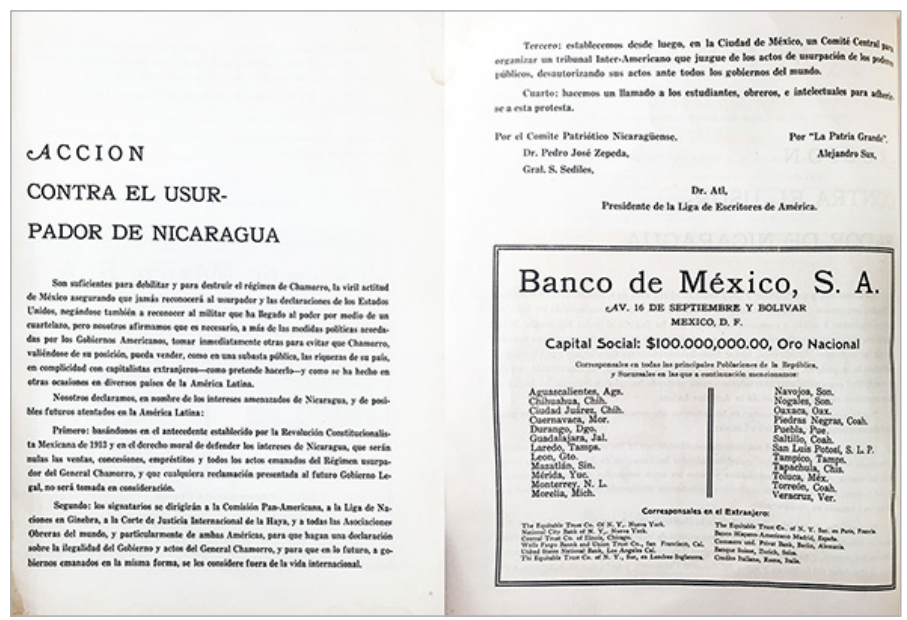

Dr. Atl, Alejandro Sux y el Comité Patriótico Nicaragüense, "Acción contra el usurpador de Nicaragua", ibid., 1-2. 


\section{Conclusiones}

Con apenas cinco números publicados, la revista América, dirigida por el Dr. Atl, destaca debido a la relevancia y particularidad de sus propuestas. Por un lado, comparte con una serie de revistas nacionales (Forma y Mexican Folkways) y regionales (Amauta y Boletín Titikaka) objetivos vinculados a consolidar un proceso político y cultural capaz de responder a las exigencias de los contextos locales e internacionales.

Como muchas de las revistas culturales y de vanguardia de la década de 1920, América comparte la expectativa en la organización de publicaciones periódicas de generar idearios que tuvieran un impacto directo en el acontecer de las naciones y, también en el caso de la causa antiimperialista, en el futuro del hemisferio, en vínculo con países del Caribe, Centroamérica y Sudamérica, tales como Cuba, Honduras, Nicaragua y Perú, al igual que el diálogo directo con otras publicaciones de similar itinerario político, por ejemplo la revista Amauta de José Carlos Mariátegui.

América representa un momento determinante para el Dr. Atl, que le permitió recuperar y renovar proyectos políticos y editoriales como el periódico anarquista L'Action d'Art (1912-1913) y la publicación revolucionaria La Vanguardia (1915), además de reafirmar nuevos aportes. Por otro lado, esta revista fue concebida para difundir un programa editorial más amplio, el cual buscó poner en marcha distintos aspectos de la producción escrita, que son subrayados en la misma publicación: la relevancia del libro, la insistencia en un mercado regional y la propuesta de creación de un diccionario local.

Este artículo se centra en explorar un mecanismo específico de la resistencia colonial e imperial. Destaca un paralelismo que existe entre territorio y lenguaje. Al nombrar América a esta revista, Atl apuntala y reclama un contexto específico. Las formas de representación del paisaje y del continente expuestas al interior de la publicación son expresiones culturales, literarias y lingüísticas. Si en otros escritos destacó a partir de un sentido económico -indisociable del político-, las cuestiones materiales, simbólicas, tectónicas, este breve episodio incluye, en dicho repertorio, la cuestión del habla y la escritura.

Este último aspecto enmarca la obra de Atl al centro de una línea de debate concreta, aquélla que pensó en las particularidades de la lengua en México y la creación de lenguajes utópicos, ${ }^{94}$ como opción efectiva para la vanguardia

94 Jorge Schwartz, "Lenguajes utópicos. 'Nuestra ortografia bangwardista': tradición y 
y medio eficaz para consolidar una identidad. Estos acercamientos correspondieron a "una opinión de parricidio lingüístico frente a la herencia colonial"95 $y_{\text {, }}$ para la etapa de consolidación del proyecto indigenista, sumaron un elemento que respondió a un intento de reivindicación, no sin dejar de implicar la violencia de la aculturación.

\section{Referencias}

Aguilar Gil, Yásnaya Elena. ¿Nunca más un México sin nosotros? San Cristóbal de las Casas, Oaxaca: CIDECI-Unitierra Chiapas, 2018.

América. Magazine Mensual. Órgano de la Liga de Escritores de América, núms. 1-5 (febrero-junio de 1926).

Antliff, Mark. "Cubism, Futurism, Anarchism. The 'Aestheticism' of the L'Action d'Art Group". Oxford Art Journal 21, núm. 2 (1998): 101-120.

Barquera, Rebeca. "Los atlcolors de Dr. Atl en las obras más representativas del Museo Nacional de Arte". Museo Nacional de Arte, 17 de mayo de 2021. Acceso el 15 de julio de 2021. https://www.facebook.com/watch/?extid =SEO----\&v=248348717070785.

Barquera, Rebeca y Andrea García. "Páginas de acción continental. La revista América del Dr. Atl". Reflexiones Marginales, núm. 51 (2019).

Bojórquez, Alfredo. "Cultura literaria. En la segunda etapa de ¡Luz! (1917-1918)". Tesis de maestría. Colegio de Letras Mexicanas, 2019.

Carpentier, Alejo. "Creadores de hoy. El arte de José Clemente Orozco". En Alejo Carpentier. Obras Completas IX. Crónicas 2. Arte, literatura, política. México: Siglo XXI, 1986.

Carpenter, Alejo. "Diego Rivera, pintor mexicano". En Alejo Carpentier. Obras Completas IX. Crónicas 2. Arte, literatura, política. México: Siglo XXI, 1986. Castillo Ledón, Luis. Hidalgo. La vida de un héroe. Tomo 1. México: Instituto Nacional de Estudios Históricos de las Revoluciones de México / Gobierno del Estado de Hidalgo, 2008.

Dr. Atl, inventor del paisaje. México: Fomento Cultural Banamex, 1978.

Dr. Atl, pinturas y dibujos. Prólogo de Carlos Pellicer. México: Fondo Editorial de la Plástica Mexicana, 1974.

ruptura en los proyectos lingüísticos de los años veinte", en América Latina. Palavra, Literatura e Cultura. Vol. 3. Cultura e Modernidade (Campinas: Editorial da Unicamp, 1995).

${ }^{95}$ Cynthia Vich, "Ortografía indoamericana, vanguardismo e identidad nacional en Boletín Titikaka", Kipus. Revista Andina de Letras, núm. 5 (1996): 26. 
Dr. Atl. A los pueblos de América. Se impone la defensa del continente contra la política de Roosevelt. México: s. e. 1941.

Dr. Atl. Ante la carroña de Ginebra. México: Polis, 1938.

Dr. Atl. Las artes populares. México: Cvltvra, 1921.

Dr. Atl. Las artes populares en México. México: s. e., 1922.

Dr. Atl. "Cinemática mexicana". Amauta. Revista Mensual de Cultura (noviembre de 1926).

Dr. Atl. Cómo nace y crece un volcán. México: Ed. Stylo, 1950.

Dr. Atl. Gentes profanas del convento. México: Senado de la República, 2003.

Dr. Atl. ¡Oro! Más oro: El mundo lo necesita: México puede dárselo. México: Edición Botas, 1936.

Dr. Atl. Paz, neutralidad, guerra. México: s. e., 1939.

Dr. Atl. Petróleo en el Valle de Méjico: Una golden line en la altiplanicie de Anáhuac. México: Polis, 1938.

Dr. Atl. "Prólogo" a Catálogo de la primera exposición de las Escuelas de Pintura al Aire Libre. Palacio de Minería, 22 al 31 de agosto de 1925. Universidad Nacional de México, 1925.

Dr. Atl. Quiénes ganarán la guerra. México: s. e., 1940.

Dr. Atl, Manuel Toussaint y José R. Benítez. Las iglesias de México. México: Secretaría de Hacienda, 1924.

Espejo, Beatriz. Dr. Atl: El paisaje como pasión. México: Fondo Editorial de la Plástica Mexicana, 1994.

Garcés V., Fernando. "Políticas del conocimiento y la colonialidad lingüística y epistémica". En Pensamiento crítico y matriz (de)colonial. Reflexiones latinoamericanas. Coordinación de Catherine Walsh, 137-168. Quito, Ecuador: Universidad Andina Simón Bolívar / Abya Yala, 2005.

Gelado, Viviana. Poéticas de la transgresión: vanguardia y cultura popular en los años veinte en América Latina. Buenos Aires: Corregidor, 2007.

González Matute, Laura. "Proyectos educativos de la posrevolución. Las escuelas al aire libre". Discurso Visual, CENIDIAP. Acceso el 17 de julio de 2021. http:// discursovisual.net/dvweb10/agora/agolaura.htm.

González Mello, Renato. "Diego Rivera, José Vasconcelos y los murales de la SEP". Colegio Nacional, marzo de 2021. Acervo de la Fototeca Nacional. Acceso el 20 de julio de 2021. https://www.youtube.com/watch?v=bB8SGYN1y-c. González Mello, Renato. "El Dr. Atl. El arcoiris y los fabricantes de células". En Vanguardia y experimentación en México, 1910-1950. Edición de Renato 
González Mello y Anthony Stanton, 93-99. México: Museo Nacional de Arte, 2013.

González Mello, Renato y Deborah Dorotinsky, eds. Encauzar la mirada. Arquitectura, pedagogía e imágenes en México, 1920-1950. México: Universidad Nacional Autónoma de México, Instituto de Investigaciones Estéticas, 2010. Hernández Campos, Jorge et al. Dr. Atl: Conciencia y paisaje. México: Universidad Nacional Autónoma de México, Dirección General de Difusión Cultural / Instituto Nacional de Bellas Artes, Museo Nacional de Arte, 1985.

Ibarra Chávez, Fernando. Escritores de imágenes y pintores de discursos. Literatura y crítica de arte en la prensa cultural de México (1900-1930). Heúresis. México: Universidad Nacional Autónoma de México, Facultad de Filosofía y Letras, Dirección General de Asuntos del Personal Académico, 2020. PDF. Acceso el 5 de agosto de 2021. http://ru.atheneadigital.filos.unam.mx/ jspui/handle/FFYL_UNAM/2502.

Knight, Alan. "Empire in the Americas. Historical Reflections". En Empire and Dissent. The United States and Latin America. Edición de Fred Rosen. American Encounters/Global Interactions, 23-52. Durnham, NC: Duke University Press, 2008. https://doi.org/10.2307/j.ctv120qs80.

Luna Arroyo, Antonio. El Dr. Atl: paisajista puro. Sinopsis de su vida y su pintura. México: Cvltvra, 1952.

Majluf, Natalia y Beverly Adams, eds. Redes de vanguardia. Amauta y América Latina, 1926-1930. Lima; Madrid: Asociación Museo de Arte de Lima - MALI / Museo Nacional Centro de Arte Reina Sofía, 2019.

Medina, Cuauhtémoc. Olinka: la ciudad ideal de Atl. México: El Colegio Nacional, 2018.

Olvera García Jorge, coord. Ensayo. Colección Horacio Zúñiga. La luz del conocimiento. Tomo VI. Estado de México: Universidad Autónoma del Estado de México, 2016.

Pellicer, Carlos. "Prólogo" a Dr. Atl, pinturas y paisajes. México: Fondo Editorial de la Plástica Mexicana, 1974.

"PROCLAMA del comité ORGANIZADOR de la LIGA de Escritores de AMÉRICA". Horizonte, núm. 1 (abril de 1926).

Quevedo, Francisco. "El alma de nuestra raza y el folklore artístico". Revista de Revistas. El Semanario Nacional 7, núm. 323 (julio de 1916).

Rivera Cusicanqui, Silvia. "La raíz: colonizadores y colonizados". En Violencias encubiertas en Bolivia. Tomo 1, Cultura y Política. Edición de Xavier Albó y Raúl Barrios. La Paz: CipcaAruwiyiri, 1993. 
Rodríguez, Miguel. "'Coincidencias': la ortografía en la construcción de las naciones hispanoamericanas". Secuencias, núm. 54 (septiembre-diciembre de 2002): 67-87. Acceso el 25 de marzo de 2021. http://dx.doi.org/10.18234/ secuencia.v0i54.788.

Rogers, Geraldine. "Las revistas como dispositivos de exhibición". En Revistas, archivo y exposición: Publicaciones periódicas argentinas del siglo XX. Edición de Verónica Delgado y Geraldine Rogers, 11-19. La Plata: Universidad Nacional de La Plata, Facultad de Humanidades y Ciencias de la Educación, 2019.

Romero, Rosalía. "Anarchism and Visual Culture in Mexico, 1910-1950". Tesis de doctorado. Durnham, Duke University, 2019.

Rosa, Natalia de la. "Aesthetic Constructions of Latin American Reality. AvantGarde Dialogues Between Mexico and Peru, 1926-1930". En Redes de vanguardia. Amauta y América Latina, 1926-1930. Edición de Natalia Majluf y Beverly Adams, 150-163. Lima; Madrid: Asociación Museo de Arte de Lima - MALI / Museo Nacional Centro de Arte Reina Sofía, 2019.

Rosa, Natalia de la. "Vida Americana, 1919-1921. Redes conceptuales en torno a un proyecto trans-continental de vanguardia". Artl@s Bulletin 3, núm. 2 (2014): Article 2.

Rosen, Fred. "Introduction" a Empire and Dissent. The United States and Latin America. Edición de Fred Rosen. American Encounters/Global Interactions, 1-20. Durnham, NC: Duke University Press, 2008. https://doi.org/ 10.2307/j.ctv120qs80.

Sáenz, Olga. El símbolo y la acción. Vida y obra de Gerardo Murillo, el Dr. Atl. México: El Colegio Nacional, 2017.

Sánchez Rodríguez, Ángel. "Il Superuomo ed Energeia, la decima musa: La influencia de D’Annunzio en la aproximación ideológica del Dr. Atl al fascismo". En De Dante a Camilleri: Estudios sobre literatura y cultura italiana. Cátedra Extraordinaria Italo Calvino. XIII Jornadas Internacionales de Estudios Italianos, 6-10 de noviembre de 2017. México: Universidad Nacional Autónoma de México, Facultad de Filosofía y Letras, 2020. Acceso el 5 de agosto de 2021. http://ru.atheneadigital.filos.unam.mx/jspui//bitstream/ FFYL_UNAM/2527/1/LONGHITANO-IBARRA-de\%20dante\%20a\%20cami lleri.pdf.

Schwartz, Jorge. "Lenguajes utópicos. 'Nuestra ortografia bangwardista': tradición y ruptura en los proyectos lingüísticos de los años veinte". En América 
Latina. Palavra, Literatura e Cultura. Vol. 3. Cultura e Modernidade. Campinas: Editorial da Unicamp, 1995.

Schwartz, Jorge. Las vanguardias latinoamericanas. Textos programáticos y críticos. 1a. reimpresión. Traducción de Estela Dos Santos. México: Fondo de Cultura Económica, 2002.

Torijano, Delfino. "La unigrafía de la lengua". América. Magazine Mensual. Órgano de la Liga de Escritores de América, núms. 4-5 (mayo-junio de 1926).

Vargas Parra, Daniel. "Ecuación Eureka. Del expediente Suárez y la transformación de la materia". Texto inédito.

Vich, Cynthia. "Ortografía indoamericana, vanguardismo e identidad nacional en Boletín Titikaka". Kipus. Revista Andina de Letras, núm. 5 (1996): 26.

Viu, Antonia. Materialidades de lo impreso: revistas latinoamericanas (19101950). Santiago de Chile: Metales Pesados, 2019.

Wallerstein, Immanuel. World-System Analysis: An Introduction. Durham: Duke University Press, 2004.

Yankelevich, Pablo. Miradas australes. Propaganda, cabildeo y proyección de la Revolución mexicana en el Río de la Plata. México: Instituto Nacional de Estudios Históricos de la Revolución Mexicana / Secretaría de Relaciones Exteriores, 1997.

Zúñiga, Horacio. "La emancipación de la lengua". América. Magazine Mensual. Órgano de la Liga de Escritores de América, núm. 3 (marzo de 1926).

Zúñiga, Horacio. "La emancipación de la lengua". En Ensayo. Colección Horacio Zúñiga. La luz del conocimiento. Tomo VI. Coordinación de Jorge Olvera García, 89-92. Estado de México: Universidad Autónoma del Estado de México, 2016. 